SAND90-7076

Unlimited Release

Distribution

Printed November 1990

\title{
Crack Closure and Healing Studies in WIPP Salt Using Compressional Wave Velocity and Attenuation Measurements: Test Methods and Results*
}

Nancy S. Brodsky

DE91 006430

$\mathrm{RE} / \mathrm{SPEC}$ Inc.

\section{ABSTRACT}

Compressional wave ultrasonic data were used to qualitatively assess the extent of crack closure during hydrostatic compression of damaged specimens of WIPP salt. Cracks were introduced during constant strain-rate triaxial tests at low confining pressure $(0.5 \mathrm{MPa})$ as specimens were taken to either $0.5,1.0$, or 1.5 percent 8xial strain. For three specimens taken to 1.0 percent axial strain, the pressure was increased to 5,10 , or $15 \mathrm{MPa}$. For the remaining specimens, pressure was raised to $15 \mathrm{MPa}$. Waveforms for compressional waves traveling both parallel and perpendicular to the direction of maximum principal stress were measured in the unidamaged state, during constant strain-rate tests, and then monitored as functions of time while the specimens were held at pressure. Both wave velocities and amplitudes increased over time at pressure, indicating that cracks closed and perhaps healed. The recovery of ultrasonic wave characteristics depended upon both pressure and damage level. The higher the pressure, the greater the velocity recovery; however, amplitude recovery showed no clear correlation with pressure. For both amplitudes and velocities, recoveries were greatest in the specimens with the least damage.

Two different data interpretations are presented for the inverse correlation between velocity and amplitude recoveries and damage level. The first explanation is based entirely upon brittle deformation processes. For cracks to close relatively quickly, crack walls must remain close to their original geometries. For higher levels of damage, crack surfaces are offset and may not reclose immediately upon pressurization. The second explanation involves plastic deformation mechanisms. During constant-strain-rate triaxial testing, the hardness of the microstructure increases as cracks are introduced. The increased hardness causes the creep rate for crack closure to be lower in specimens taken to higher levels of damage. For both data interpretatic $7 s$, complete crack closure and healing are expected if hydrostatic stress is maintained for an extended time period.

* The work described in this report was performed for Sendia National Laboratories under Contract No. 23-8484. 


\section{TABLE OF CONTENTS}

1.0 INTRODUCTION . . . . . . . . . . . . . . . . 1

1.1 BACKGROUND . . . . . . . . . . . . . . . 1

$1.2 \mathrm{SCOPE} \ldots \ldots \ldots \ldots \ldots$. . . . . . . . . . . 2

1.3 REPORT ORGANIZATION . . . . . . . . . . . . . 2

2.0 SPECIMENS . . . . . . . . . . . . . . . . . . . . . . . 3

2.1 SAMPLE ACQUISITION AND DESCRIPTION . . . . . . . 3

2.2 SPECIMEN PREPARATION . . . . . . . . . . . . . 3

3.0 EXPERIMENTAL TECHNIQUE . . . . . . . . . . . . . . 5

3.1 APPARATUS AND INSTRUMENTATION . . . . . . . . 5

3.1.1 Load Frame and Pressure Vessel . . . . . . . . . . . . 5

3.1.2 Strain Measurements . . . . . . . . . . . . . . . . 5

3.1.3 Ultrasonic Velocity Measurement System . . . . . . . . 7

3.1.4 Jacketing . . . . . . . . . . . . . . . . . . . 7

3.2 PROCEDURES . . . . . . . . . . . . . . . . . . 9

3.2.1 Calibration Procedures for Force, Pressure, and Displacement 9

3.2.2 Measurements of Time Delays for Ultrasonic System . . . 9

3.2.3 Experimental Procedure . . . . . . . . . . . . . . . . 10

3.3 VALIDATION TESTS FOR ULTRASONIC SYSTEM . . . . . . 12

3.4 DATA ACQUISITION AND REDUCTION . . . . . . . . 14

4.0 RESULTS . . . . . . . . . . . . . . . . . . . . . . . . . . 19

4.1 CONSTANT STRAIN-RATE TRIAXIAL LOADING DATA . . 19

4.1.1 Stress-Strain Data . . . . . . . . . . . . . . . 19

4.1.2 Amplitude and Velocity Data . . . . . . . . . . . 19

4.2 CRACK ClOSURE AND HEALING PHASE . . . . . . . . 23

4.2.1 Strain-Time Data . . . . . . . . . . . . . . . . . . . 23

4.2.2 Amplitude Changes as a Function of Damage Level and Pressure . . . . . . . . . . . . . . . . . 23

4.2.3 Velocity Changes as a Function of Damage Level and Pressure 28 


\section{TABLE OF CONTENTS}

(CONTINUED)

5.0 DISCUSSION . . . . . . . . . . . . . . . . . . 31

5.1 RELEVANT MECHANISMS FOR WAVE ATTENUATION AND

VELOCITY CHANGES . . . . . . . . . . . . . 31

5.2 INTERPRETATION OF DATA . . . . . . . . 31

6.0 SUMMARY AND CONCLUSIONS . . . . . . . . 35

T.0 REFERENCES . . . . . . . . . . . . . . . . . . . . 37 


\section{LIST OF FIGURES}

3-1 Load Frame, Pressure Vessel, and Strain Extensometry Used for Crack Healing Tests. . . . . . . . . . . . . . . . . . . 6

3-2 Schematic Diagram of Ultrasonic Velocity Measurement System. . . 8

3-3 Schematic Diagram of Pressure History During a Crack Healing Test at $10 \mathrm{MPa}$ Confining Pressure. . . . . . . . . . . . . . .

3-4 Normalized Amplitudes (a) and Travel Times (b) for the First Peak of the Compressional Wave, as Functions of Time at $15 \mathrm{MPa}$ Confining Pressure for an Aluminum Specimen. . . . . . . . . . .

3-5 Validation Test on Aluminum. Normalized Amplitudes (a) and Travel Times (b) for the First Peak of the Axially Oriented Compressional Wave, as Functions of Pressure Cycling to $15 \mathrm{MPa}$. Circles Show Increasing Pressure, Triangles Show Decreasing Pressure. . . . .

3-6 Waveforms Obtained During Crack Closure and Healing for Test 5. Initial Waveforms for P-Perpendicular (a) and P-Parallel (b), and Waveforms Obtained After 3 Days at Pressure for P-Perpendicular (c) and P-Parallel (d). . . . . . . . . . . . . . . .

4-1 Stress-Strain Curves for Constant Strain-Rate Triaxial Compression Test Segments at $0.5 \mathrm{MPa}$ Confining Pressure. Stress is the Axial Stress Minus the Confining Pressure. . . . . . . . . . . . . . . 20

4-2 Normalized Peak-to-Peak Amplitudes as a Function of Axial Strain for Constant Strain-Rate Triaxial Compression Test Segments. Test Numbers Correspond to Table 3-1.

4-3 Normalized Velocities as a Function of Axial Strain for Constant StrainRate Triaxial Compression Segments. Test Numbers Correspond to Table 3-1. . . . . . . . . . . . . . . . . . . . . . . .

4-4 Axial Strains as a Function of Time During the Crack Closure and Healing Segment: (a) Damage Level of 0.5 Percent, (b) Damage Level of 1.0 Percent, and (c) Damage Level of 1.5 Percent.

4-5 Lateral Strains as a Function of Time During the Crack Closure and Healing Segment: (a) Damage Level of 0.5 Percent, (b) Damage Level of 1.0 Percent, and (c) Damage Level of 1.5 Percent.

4-6 Normalized Peak-to-Peak Amplitudes as Functions of Time During the Crack Closure and Healing Phase. 


\section{LIST OF FIGURES}

(Continued)

4-7 Stress-Strain Curves for All Tests Taken to 1.0 Percent Axial Strain. 27

4-8 Normalized Velocities as Functions of Time During the Crack Closure and Healing Phase. . . . . . . . . . . . . . . . . . . . . . . 29

5-1 Ratio of Amplitudes at Points $E$ and $B$, and Ratio of Velocities at Points $\mathrm{E}$ and $\mathrm{B}$ as a Function of Pressure and Damage Level. $P_{\perp}: \mathrm{X}$; $P_{\|}:$O................... 


\section{LIST OF TABLES}

3-1 Test Matrix . . . . . . . . . . . . . . . . . . 10 


\subsection{INTRODUCTION}

\subsection{BACKGROUND}

The Waste Isolation Pilot Plant (WIPP) is a research and development facility sited in a bedded salt formation in southeastern New Mexico. It is located in the Salado Formation of the Delaware Basin at a depth of approximately $660 \mathrm{~m}$. The purpose of the WIPP is to demonstrate the technology for safe handling and disposal of radioactive TRU wastes produced by defense activities. Advanced technologies are being developed to supplement existing practices for design of underground openings because little experience is applicable to the environmental conditions and the very long times for which the waste must be isolated.

During excavations of openings in salt, deviatoric stress fields develop that generate microcracks in the salt surrounding the opening. These microcracks may increase permeability and therefore can increase fluid flow if interstitial brine is present. Salt is known for its ability to creep at relatively low stresses and temperatures. Creep relaxes tensile stresses and allows in situ compressive stresses to close excavation-induced fractures enabling them to heal. Here, crack healing is the process whereby the normal salt lattice bonds are reestablished and the material strength is returned across the site of the healed crack. Crack closure is a prerequisite to crack healing; however, crack closure implies that although the crack surfaces come together in close proximity, the surfaces remain distinct and no mechanical strength returns across the crack.

To date, very few studies have actually documented the process of crack healing. $\Lambda$ study done by Costin and Wawersik [1980] showed that tensile fractures in salt heal when subjected to pressures of 10 to $35 \mathrm{MPa}$. They measured fracture toughness in short rod specimens of salt, pieced the specimens back together, and jacketed them. These jacketed specimens were then subjected to hydrostatic stress for varied lengths of time and at two temperatures before being retested. Typically, specimens regained 70 to 80 percent of their original fracture toughness.

Ultrasonic wave velocities and attenuation have been used extensively as indicators of crack development in geologic materials. Increases in ultrasonic velocity accompany hydrostatic compression of rocks as shown by Birch $[1960,1961]$ for compressional waves and by Simmons [1964] for shear waves. These increases in velocity have been attributed to crack closure and densification of the material in response to the hydrostatic stress. Seismic wave velocities and changes in wave attenuation have also been used to measure increases in dilatancy in rock /Gupta, 1973; Hadley, 1975; Soga et al., 1978; Sobolev et al., 1978; Spetzler et al., 1981; Granryd et al., 1983; Shea and Hanson, 1988]. Changes in compressional wave velocity and aitenuation have also been used to assess the size of the disturbed zone associated with mining in salt at the WIPP [Holcomb, 1988]. 
The objective of this study was to assess the effects of time, hydrostatic stress, and damage level on crack closure and healing. Brittle fractures were introduced into WIPP salt specimens during triaxial compression constant strain-rate tests at very low confining pressure $(0.5 \mathrm{MPa})$. Specimens were then taken to elevated pressure, and subsequent increases in ultrasonic velocity and in wave amplitude were measured. These changes in ultrasonic wave characteristics, measured over time at pressure, were interpreted as indicators of microcrack closure and possibly healing. The wave characteristics were compared for different levels of pressure and different levels of induced damage.

Wave characteristics were also measured at low pressure before and after hydrostatic compression to get an indication of the extent of crack healing. (Healed cracks are defined here as cracks that remained closed when hydrostatic stress was released.) Unfortunately, the experimental uncertainty associated with these data was large and no conclusive statement can be made about the proportion of closed cracks that also healed.

\subsection{SCOPE}

Two experiments were designed to determine the influence of time, hydrostatic pressure, and damage level on crack closure and healing in WIPP salt. Each experiment consisted of at least three tests. In the first experiment, crack closure and healing, as indicated by changes in ultrasonic compressional wave amplitudes and velocities, were measured as a function of time at pressure for pressures of 5 , 10 , and $15 \mathrm{MPa}$. All specimens were damaged during constant strain-rate triaxial compression tests that were terminated at 1.0 percent axial strain. Each was then held at one of the three specified confining pressures. The recoveries of amplitudre and velocities were measured as a function of time at each pressure. In the second experiment, the effect of different damage levels was investigated. Damage was again induced during constant strain-rate triaxial compression tests; however, the tests were terminated at three different prescribed levels of axial strain, 0.5, 1.0, and 1.5 percent. Then, all specimens were held at a pressure of $15 \mathrm{MPa}$. Again, the recoveries of amplitudes and velocities were measured as functions of time at pressure. This report describes the techniques used in these tests, presents the results, and gives an interpretation of the results.

\subsection{REPORT ORGANIZATION}

This report consists of seven chapters. Chapter 1 is introductory. Chapter 2 contains a description of the specimens and specimen preparation. The testing equipment, procedures, results of calibration tests, data acquisition, and data reduction methods are given in Chapter 3. Experimental results are presented in Chapter 4 and discussed in Chapter 5. Chapter 6 presents the summary and conclusions for this study, and references are given in Chapter 7. 


\subsection{SPECIMENS}

\subsection{SAMPLE ACQUISITION AND DESCRIPTION}

Salt samples were obtained from the WIPP site in Carlsbad, New Mexico. The samples were recored from larger, 0.4-m-diameter cores taken froin horizontal drill holes in one of the ribs of Room $\mathrm{C}$ in the experimental area. The large diameter cores are from hole C1X01, as recorded in the Sandia QA System. The large diameter cores were placed in padded wooden crates and shipped to the RE/SPEC laboratory in Rapid City, South Dakota, via a temperature-controlled truck to prevent freezing.

\subsection{SPECIMEN PREPARATION}

The 0.4-m-diameter core samples were sawed dry in a large band saw to produce rectangular prisms. These frisms were then subcored using saturated brine to obtain 100-mm-diameter, 200-mm-long specimens whose axes were normal to the bedding. The specimen ends were machined flat and parallel to within $0.015 \mathrm{~mm}$ by placing the specimen in a collet and mounting the collet in the jaws of a lathe. After facing one end, the collet was turned end-for-end and the other end was faced. After finishing, each specimen was assigned an identification number according to WIPP Procedure No. 092 and logged into the RE/SPEC specimen inventory along with its dimensions. 


\subsection{EXPERIMENTAL TECHNIQUE}

\subsection{APPARATUS AND INSTRUMENTATION}

\subsubsection{Load Frame and Pressure Vessel}

Tests were perforred in a computer-controlled, servohydraulic test system comprising a pressure vessel and an MTS 312.41 load frame as shown in Figure 3-1. A hydraulic actuator located in the base of the load frame was capable of applying an axial force of $500 \mathrm{kN}$. A load cell that was bolted to the movable crosshead was used to measure axial force. Pressure was measured by a strain-gage-type pressure transducer in the line between the intensifier and pressure vessel. A control console housed signal conditioni.g for the deformation transducers, as well as feedback and valve driver modules for the hydraulics. A controller was used for the actuator servoloop, and a servocontroller was used for maintaining confining pressure. This console interfaced with a DEC LSI-11/73 microprocessor to provide data acquisition and programmable control.

\subsubsection{Strain Measurements}

Specimens were instrumented with direct contact extensometers as illustrated in Figure 3-1. The axial extensometer, an MTS 632.90C-04 strain-gage-type, consisted of two sensing arms, each $100 \mathrm{~mm}$ long and mounted $180^{\circ}$ apart. The circumferential extensometer, an MTS 632.92C-05 strain-gage-type, comprised a coller-link chain wrapped around the specimen and a sensor that monitored the relative displacement of the ends of the chain as the specimen circumference changed. The relationshir hetween circumferential extensometer output and change in circumference is nonlinear but is related by simple geometry and accounted for during data reduction. During testing, the axial extensometer and the chain of the circumferential extensometer were centered with respect to the specimen midheight. The influence of changes in pressure on the outputs of the strain extensometers was measured before testing. Changes in the transducer outputs were determined by calibration using a specimen of fused quartz as described by Senseny [1987]. For the pressure range used in this study, pressure effects were shown to be negligible.

To complement the active strain measurements, specimen length and diameter were measured pre- and post-test. The differen ies between pre- and post-test measurements were used to calculate strains that were then compared with measurements made during testing. In all cases, the two strain measurements were within 30 percent of one another.

Thin $0.127 \mathrm{~mm}(0.005 \mathrm{in})$ teflon sheets that adhered to the platens were placed at both ends of the specimen to minimize end effects. Uniformity of deformation was checked by comparing post-test diameter measurements made at equally spaced 
RSI-124-89-019

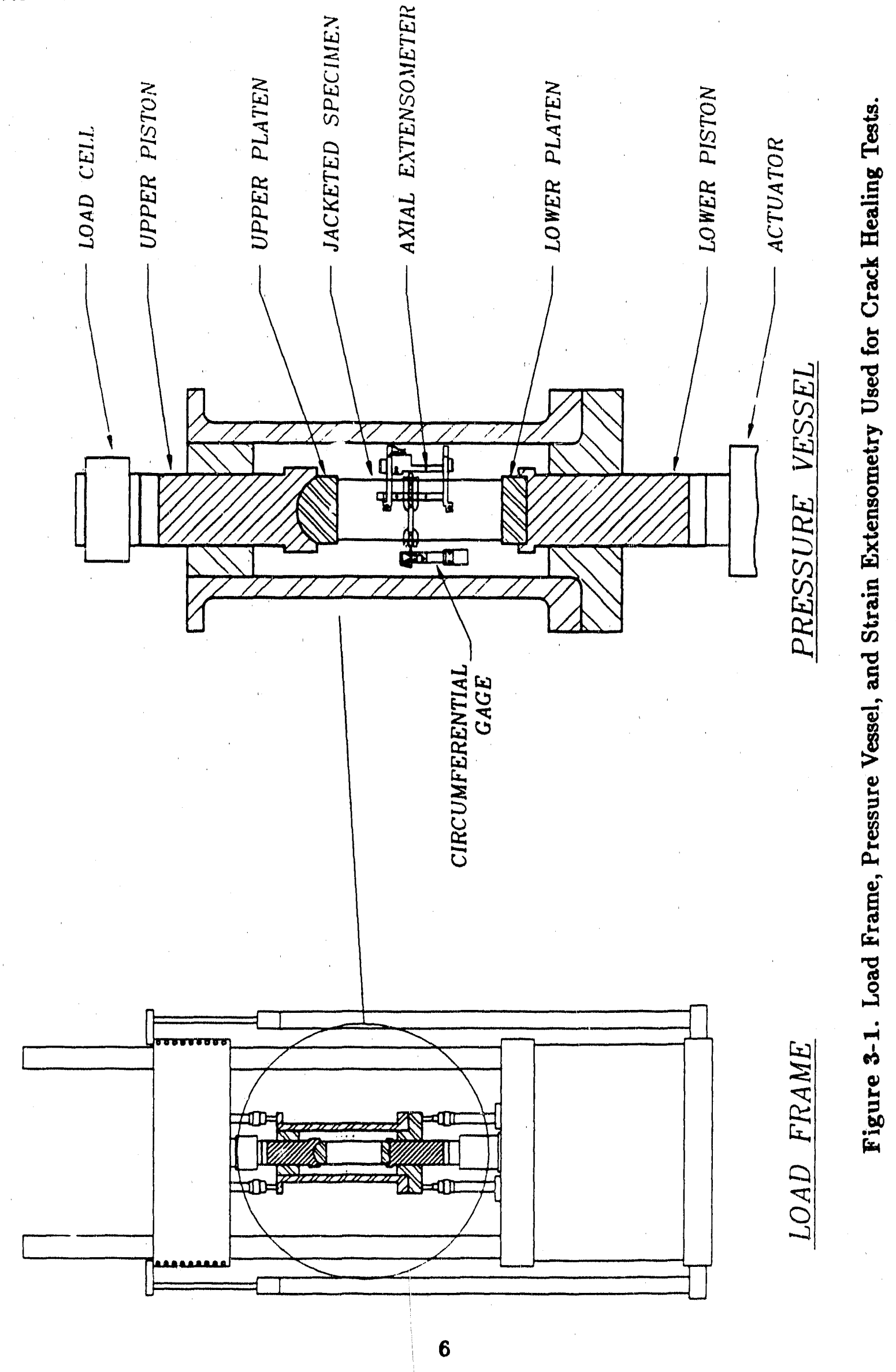


intervals along the specimen length and in two perpendicular directions. For all tests but one, the ten post-test diameter measurements were uniform to within 0.5 percent of one another. For the remaining test, only one measurement was greater than 0.5 percent.

\subsubsection{Ultrasonic Velocity Measurement System}

The ultrasonic velocity measurement system is shown schematically in Figure 3-2 and comprises two pairs of compressional wave velocity transducers, a switching box, a pulser/receiver, a preamplifier with power supply, and a digital oscilloscope. One set of velocity transducers was mounted in the platens above and below the specimen for measurements parallel to the specimen axis, and springs held a second set of transducers against the sides of the specimen for measurements perpendicular to the axis. The second set of transducers was located just above the specimen midheight to allow room for the circumferential extensometer. All transducers had a $1 \mathrm{MHz}$ resonant frequency and were $31.75 \mathrm{~mm}$ (1.25 inches) in diameter. Although the contact between the flat transducers and the cylindrical sides of the specimen formed a line, sufficient energy was transmitted across the interface to conduct these tests.

During velocity measurements, a $250-\mathrm{V}$ main pulse generated by the pulser/ receiver was sent through a switching box to one of the pulsing transducers. Simultaneously, the pulser/receiver sent a $1-\mathrm{V}$ signal to the external trigger of the oscilloscope. The main pulse traversed the specimen, and the received signal was preamplified $40 \mathrm{~dB}$ before it was sent to the pulser/receiver. The preamplifier contained a high pass filter of $0.3 \mathrm{MHz}$ to filter extraneous noise. The pulser/receiver is designed to amplify the signal either 40 or $60 \mathrm{~dB}$, and then attenuate it using fine adjustments. All signals were amplified an additional $40 \mathrm{~dB}$ and attenuated 30 to $60 \mathrm{~dB}$ to bring the maximum expected amplitudes to within $\pm 1.0 \mathrm{~V}$. Total amplifications were therefore 20 to $50 \mathrm{~dB}$. Different values of attenuation were required for different pressures. The combined RF output of the pulser/receiver (containing both the trigger pulse and amplified received signal) was sent to a digital oscilloscope. Each waveform was digitized into $2^{13}(8,192)$ points with a precision of $20 \mathrm{~ns}$. Voltage resolution was \pm 0.4 percent of full scale or $\pm 4-\mathrm{mV}$. Thirty repeated signals were averaged (except where noted in the procedure) to increase the signal-to-noise ratio. The averaged signal was recorded on diskette.

\subsubsection{Jacketing}

Ported jackets were used to shield the specimen from the silicon oil confining fluid. In this ported jacket design, holes were cut out of the Viton jackets at the velocity transducer locations and the locations required for the circumferential extensometer. The Viton was replaced with $0.051-\mathrm{mm}$-thick ( 0.002 inch) steel shims that were bonded to the remaining Viton with adhesive and held tightly against the specimen by the confining pressure. All ultrasonic transducers were immersed in 


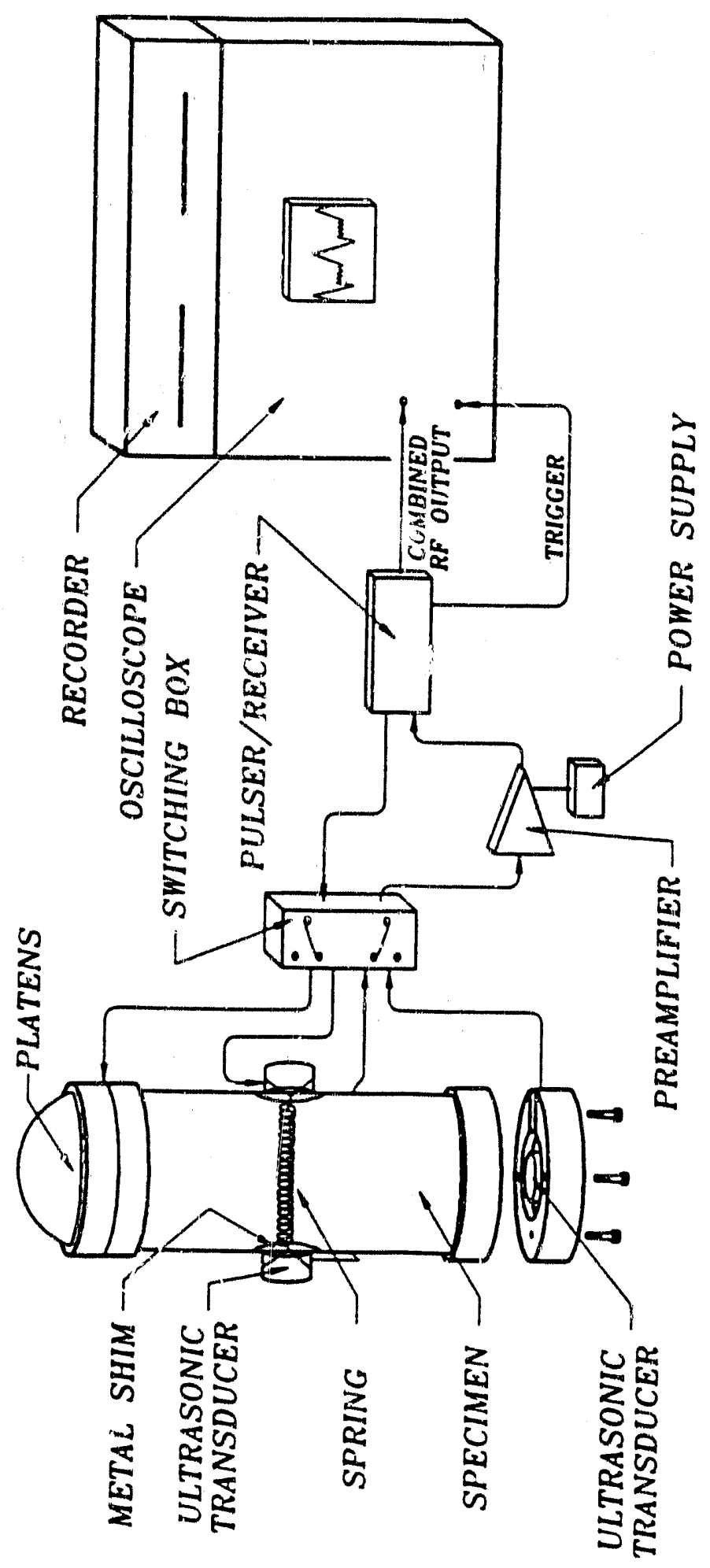

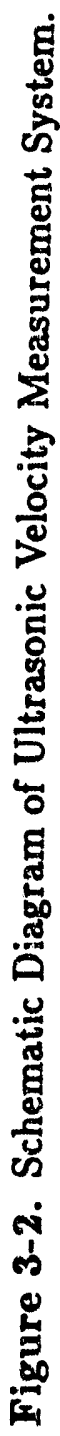


confining fluid. A thin film of this fluid acted as a couplant between the transducers and platens for transducers mounted in the platens, and between the transducers and metal shims of the ported jacket for transducers mounted on the sides of the specimen. For waves traveling parallel to the specimen axis, a thin film of P-wave couplant (glycerine) was placed between the flat ends of the specimen and the teflen sheets used to minimize end effects.

\subsection{PROCEDURES}

\subsubsection{Calibration Procedures for Force, Pressure, and Displacement}

All force, pressure, and displacement sensing elements were calibrated in their normal operating orientations on the test sysiem, and outputs were observed at normal data collection points. By using this approach, the signal conditioners, filters, and analog-to-digital converters were all included within the "end-to-end" calibration. Calibratinzs for force, pressure, and displacement were performed by determining the best straight-line fit to indicated readings versus standard input, after applying the standard input in 20 equal steps. The calibration constants were then verified by applying the standard input in ten equal steps over the calibrated range. The transducer response at each step was predicted using the calibration constants. The process of calibration/verification was repeated until the predicted values feil within acceptable levels of error: 1.0 percent of reading for load and pressure calibrations and 2.0 percent of reading for displacement calibrations.

At the conclusion of the testing program, the verification steps were repeated. For all force, prassure, and displacement sensing elevnents, the calibration constants reverified to within acceptable errors.

\subsubsection{Measurements of Time Delays for Ultrasonic System}

To accurately determine the time required for an acoustic signal to traverse a specimen, one must first measure the time required for the signal to travel through the external portions of the transducer, the platens, and the teflon sheets that were used in the experimental assembly. Any lack of simultaneity between the main pulse and the pulse to the oscilloscope trigger must also be measured. Using the measurement system described in Section 3.1.3 but using no specimen (i.e., signals traveled platen to platen), a delay time of $2.86 \mu \mathrm{s}$ was measured. This delay was the correction applied to signals traveling parallel to the specimen axis. The delay time for waves traveling perpendicular to the axis was determined by measuring the time required for a wave to travel from transducer to transducer through two metal shims. This delay time was relatively short, $0.280 \mu \mathrm{s}$. 


\subsubsection{Experimental Procedure}

Two (xperiments were designed to test for crack closure and healing in WIPP salt as a function of time, pressure, and damage level. The test matrix used for both experiments is given in Table 3-1. Prior to testing, all specimens were preconsolidated using a hydrostatic stress of $20 \mathrm{MPa}$ for 1 week.

Table 3-1. Test Matrix

\begin{tabular}{|c|c|c|c|}
\hline Test $^{(a)}$ & $\begin{array}{c}\text { Specimen } \\
\text { ID }^{(6)}\end{array}$ & $\begin{array}{c}\text { Pressure } \\
(\mathrm{MPa})\end{array}$ & $\begin{array}{c}\text { Damage Level } \\
\text { (Axial Strain, \%) }\end{array}$ \\
\hline 1 & $\mathrm{C} 1 \mathrm{X} 01-04 / 1-4 / 2-2$ & 10 & 1.0 \\
2 & $\mathrm{C} 1 \mathrm{X} 01-03 / 1-4 / 4-2$ & 5 & 1.0 \\
3 & $\mathrm{C} 1 \mathrm{X} 01-04 / 1-2 / 4-2$ & 15 & 1.0 \\
4 & $\mathrm{C} 1 \mathrm{X} 01-04 / 1-2 / 3-2$ & 15 & 0.5 \\
5 & $\mathrm{C} 1 \mathrm{X} 01-02 / 1-4 / 4-2$ & 15 & 1.0 \\
6 & $\mathrm{C} 1 \mathrm{X} 01-02 / 1-4 / 2-2$ & 15 & 1.5 \\
7 & $\mathrm{C} 1 \mathrm{X} 01-04 / 1-4 / 4-2$ & 15 & 0.5 \\
\hline
\end{tabular}

(a) Tests are listed in the order in which they were performed.

(b) The first foul digits that follow the C1X01 designation specify the sample block. The last two digits indicate the specimen location within the block.

The purpose of the first experiment was to observe the effect of pressure on the crack closure and healing process. Tests were run at a damage level of 1.0 percent total axial strain and pressures of 5,10 , or $15 \mathrm{MPa}$. A typical load path for a test at $10 \mathrm{MPa}$ is shown in Figure 3-3 as an example of the pressure history during each test. All specimens were hydrostatically loaded to $15 \mathrm{MPa}$ and then unloaded to $0.5 \mathrm{MPa}$ (Segment 1 on Figure 3-3). Compressional waves traveling parallel and perpendicular to the specimen axis were recorded during depressurization at 15,10 , and $5 \mathrm{MPa}$, at the points marked with asterisks. These recorded waveforms were considered representative of the original state of the material. During Segment 2, (between Points $A$ and $B$ ), specirzens were loaded in triaxial compression at $0.5 \mathrm{MPa}$ confining pressure and at a constant axial strain rate of $8.7 \times 10^{-7} \mathrm{~s}^{-1}$ until axial strain reached 1.0 percent. During this step, damage was introduced in a controlled manner. Specimens were unloaded quickly at constant stress rate to a differential stress of $0.25 \mathrm{MPa}$ to maintain good axial coupling. This differential stress was superimposed on all subsequent hydrostatic stress states. Specimens were reloaded hydrostatically (during Segment 3 ) to Point $C$ to begin the crack closure and healing 


\section{SCHEMATIC DIAGRAM OF LOADNG PATH}

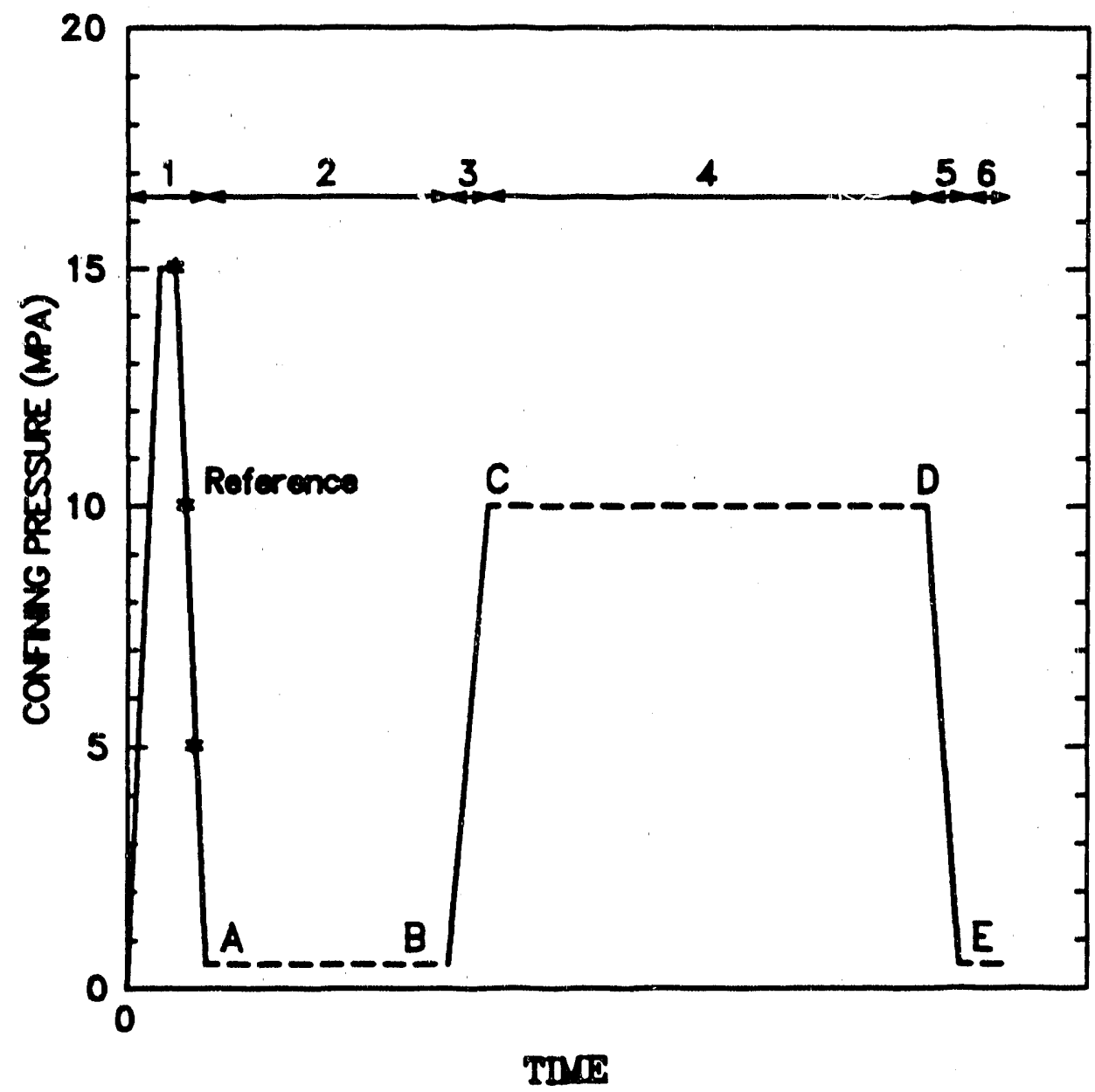

Figure 3-3. Schematic Diagram of Pressure History During a Crack Healing Test at $10 \mathrm{MPa}$ Confining Pressure. The Asterisks and Dashed Lines Indicate Where Ultrasonic Measurements Were Made. A Differential Stress of $0.25 \mathrm{MPa}$ was Superimposed on Hydrostatic Stress Levels During Segments 3, 4,5, and 6. Test Segments 1 Through 6 are as Follows: (1) Hydrostatic Loading/Unloading to Establish Reference Points; (2) Constant Strain-Rate Test to Induce Damage, Unload at Constant Stress Rate; (3) Hydrostatic Loading to Pressure; (4) Crack Closure and Healing Phase; (5) Depressurization; and (6) $0.5 \mathrm{MPa}$ Hydrostatic Stress. 
phase (Segment 4). Point $\mathrm{C}$ was at either 5,10 , or $15 \mathrm{MPa}$, although in the example shown, it is at $10 \mathrm{MPa}$. Waveforms recorded during this segment were normalized to the original values marked with asterisks. For the $10 \mathrm{MPa}$ test shown, data were normalized to the point marked "Reference" in Figure 3-3. From the work of Costin and Wawersik (1980), it is inferred that both crack closure and healing occurred during Segment 4, and so it is referred to as the crack closure and healing phase. However, the ultrasonic data obtained during this segment only provide evidence of crack closure and densification of the material. Segment 4 continued for 3 to 5 days (Points $C$ to $D$ ), after which time the hydrostatic stress was decreased (Point E). Aside from at the reference points, ultrasonic measurements were made during the constant strain-rate segment, the crack closure and healing phase, and after depressurization. These segments are shown with dashed lines in Figure 3-3.

The second experiment was designed to assess the effect of damage level on crack closure and healing. The procedure was basically the same as that described above. It differed in that all specimiens were held at the same pressure during Segment 4, $15 \mathrm{MPa}$, but maximum axiai strain levels of $0.5,1.0$, and 1.5 percent were used to introduce different levels of damage into each specimen during Segment 2, the constant strain-rate triaxial test. These relatively low values of axial strain were chosen because the ported jackets tended to rupture at 2 percent strain. The h pecimens underwent crack closure and healing during Segment 4. One test at 0.5 percent axial strain terminated after less than 2 days. Based on the first experiment, it was determined that 3 days would be sufficient to observe the effect of damage level on crack closure and healing.

\subsection{VALIDATION TESTS FOR ULTRASONIC SYSTEM}

Two tests were conducted on an aluminum specimen to determine the stability of the waveforms as a function of time at pressure and to measure pressure-dependent hysteresis of the received waveforms. A right circular cylinder of aluminum was used as a specimen. The deformation and ultrasonic transducers were set up as described for a salt test except that only axial transducers were used. The specimen and instruments were placed in a pressure vessel, and insulating materials were placed around the vessel to shield it from any temperature fluctuations. (The temperature, as measured between the vessel and the insulating materials, fluctuated by less than $\pm 0.7^{\circ} \mathrm{C}$.)

The first test was designed to determine the stability of waveforms as a function of time at pressure. Pressure was raised to $15 \mathrm{MPa}$ at a rate of $1 \mathrm{MPa}$ per minute. The system remained at pressure for approximately 4-1/2 to 5 days, during which time waveforms were recorded at least once per day. Each recorded waveform was the average of 30 sweeps. The amplitudes and travel times for the first peak of the compressional wave were tracked and the normalized data are shown in Figures $3-4 \mathrm{a}$ and 3-4b, respectively. Amplitudes and travel times were normalized to their initial values. The observed noise in the amplitude measurement was less than 


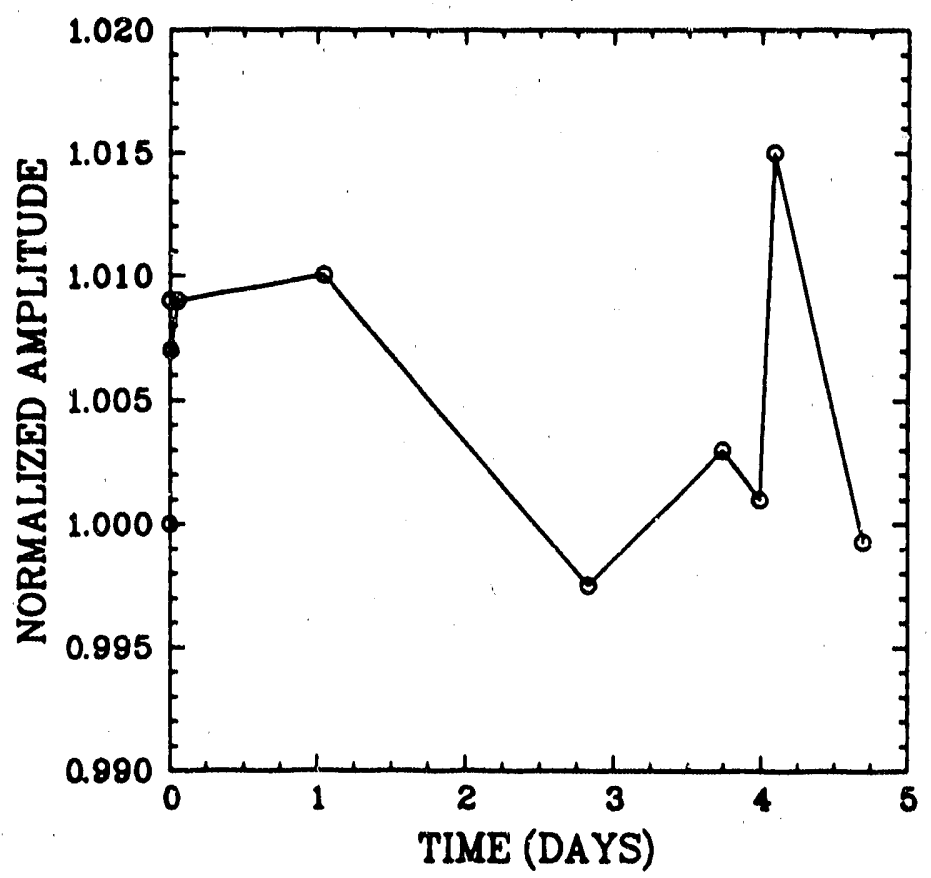

(a)

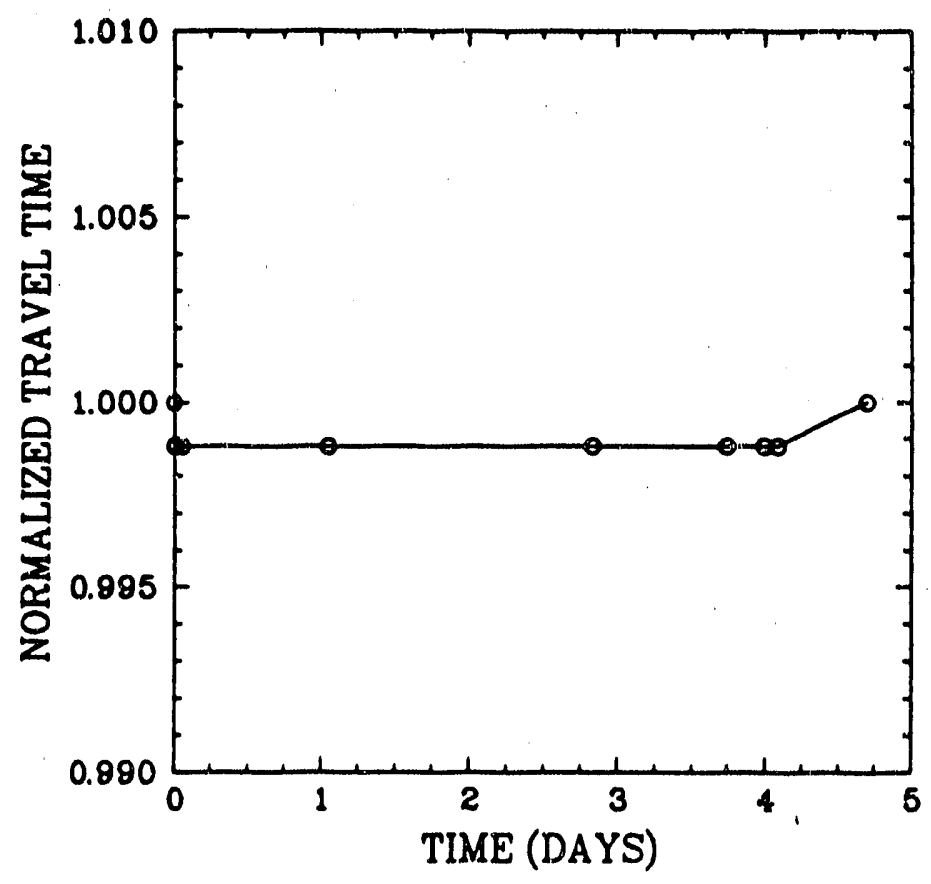

(b)

Figure 3-4. Normalized Amplitudes (a) and Travel Times (b) for the First Peak of the Compressional Wave, as Functions of Time at $15 \mathrm{MPa}$ Confining Pressure for an Aluminum Specimen. 
\pm 2 percent. Figure $3-4 \mathrm{~b}$ shows that the normalized travel times were constant to within 0.1 percent.

The second test was designed to evaluate the reproducibility of signals as a function of pressure cycling. Pressure was raised to $15 \mathrm{MPa}$, lowered to $1 \mathrm{MPa}$, raised to $15 \mathrm{MPa}$, and then lowered to $0 \mathrm{MPa}$. Waveforms were recorded at pressures of $1,3,5,7,10,12$, and $15 \mathrm{MPa}$. Again, each recorded waveform was the average of 30 sweeps. Pressure was raised and lowered at a rate to give sufficient time to record waveforms. Pressure was raised at $1 \mathrm{MPa}$ per minute, and an additional 4-minute wait was imposed at integer values of pressire.

The normalized amplicude and travel time data are plotted as functions of pressure in Figures 3-5a and 3-5b, respectively. Data were normalized to initial values. The data points which lie far off the curves at $7 \mathrm{MPa}$ are attributed to operator error in setting the attenuation factors on the pulse/receiver. (Recall from Section 3.3 that different settings were required for different pressures.) It is somewhat surprising that travel times were affected. With the exception of the scatter at $7 \mathrm{MPa}$, the normalized amplitudes vary by as much as 16 percent as a result of pressurization to $15 \mathrm{MPa}$; however, at a constant pressure of $15 \mathrm{MPa}$, the normalized amplitudes vary by only 3 percent. The variability of the amplitude data with respect to pressure is considered to be large. Therefore, amplitude measurements were not made on test specimens as a function of pressure, but instead, amplitude comparisons were made at constant pressure. The normalized travel times vary by only 0.3 percent and this is considered an acceptable reproducibility.

\subsection{DATA ACQUISITION AND REDUCTION}

During each test, time, axial force, axial strain, circumferenticl strain, temperature, and pressure were read and recorded at timed intervals. Axial stress was calculated from axial force and current specimen dimensions. During the crack closure and healing segment of the test, data were recorded every 100 seconds; during the constant axial strain-rate triaxial compression test, these data were recorded every 50 seconds. Ultrasonic data were read and recorded during the constant strain-rate triaxial compression segment and during the crack closure and healing phase. Data were read at timed intervals which began clonely spaced and decreased in frequency as time progressed. For the constant strain-rate test segment, ultrasonic data were recorded every 250 seconds (approximately every 4.2 minutes or $225 \mu \epsilon$ ) for the first 16.7 minutes, every 8.3 minutes until the segment time reached 50 minutes, and every 16.7 minutes thereafter. For the crack closure and healing segment, ultrasonic data were acquired every 8.3 minutes for the first 33 minutes, every 16.7 minutes until the total segment time reached 1.4 hours, and every 33 minutes until the time reached 2.8 hours. After this, data were read at least twice per day and more commonly five times per day. This data acquisition system was not automated. 


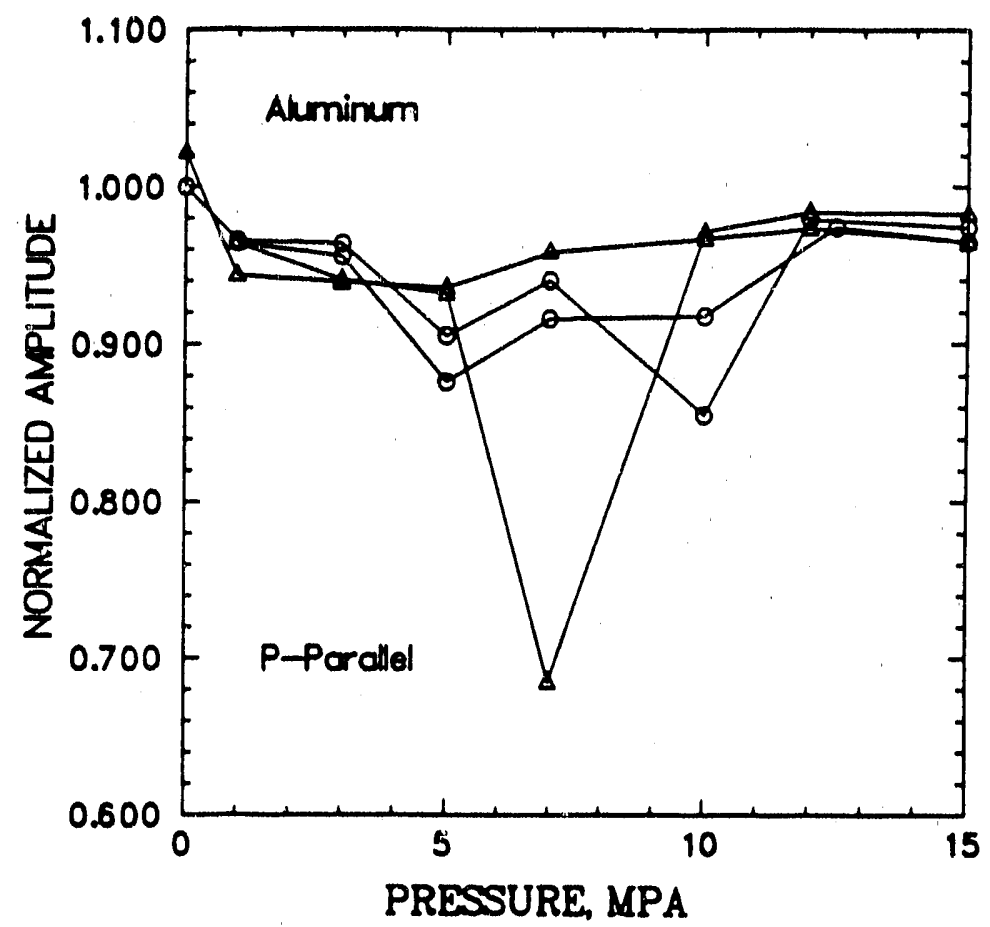

(a)

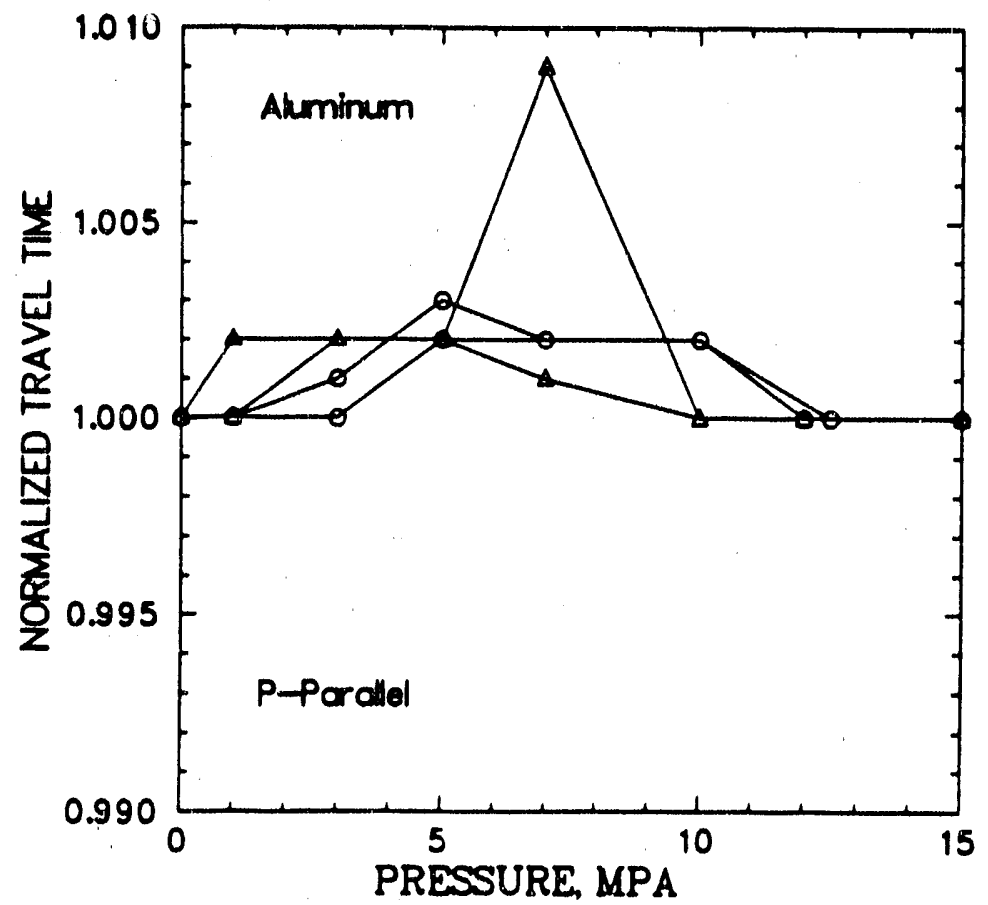

(b)

Figure 3-5. Validation Test on Aluminum. Normalized Amplitudes (a) and Travel Times (b) for the First Peak of the Axially Oriented Compressional Wave, as Functions of Pressure Cycling to $15 \mathrm{MPa}$. Circles Show Increasing Pressure, Triangles Show Decreasing Pressure. 
Arrival times and amplitudes for the first peak and first trough were read from the digital oscilloscope for each recorded waveform. Typical waveforms obtained at the start of crack closure and healing and after 3 days are shown in Figure 3-6 for Test 5, for compressional waves traveling perpendicular (Figure 3-6a and 3-6c) and parallel (Figure 3-6b and 3-6d) to the specimen axis. Initial velocities were determin $d$ using the arrival times at which the signals emerged from the noise. Changes in velocities were then tracked using the arrival times of the first peaks. In calculating velocities from travel time data, corrections were made for the transducer delay times (see Section 3.2.2) and for specimen strain. Data acquired during the constant strain-rate segments were normalized to the data obtained just prior to the initiation of loading. Data acquired during the crack closure and healing phase of the test were normalized to reference data obtained during the preliminary pressurization, as outlined in Section 3.2.3. 
RS 1-124-90-17

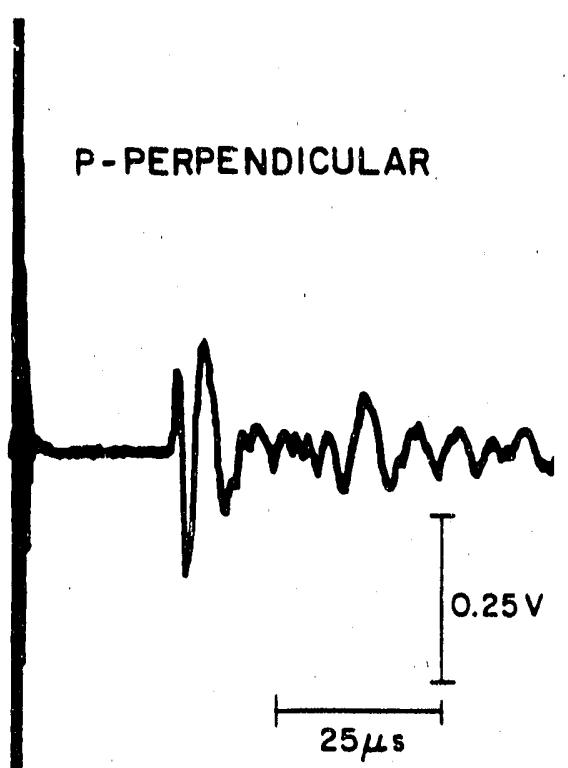

(a)

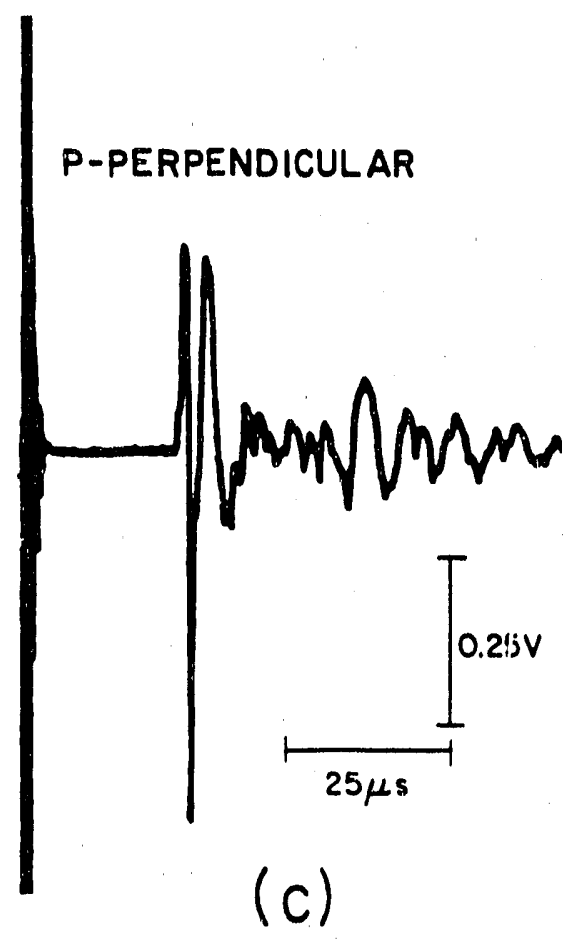

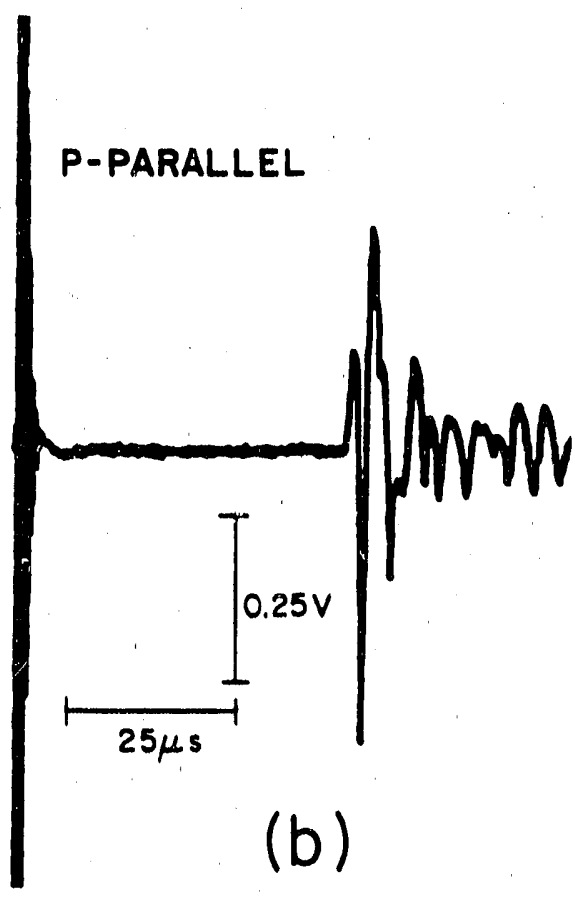

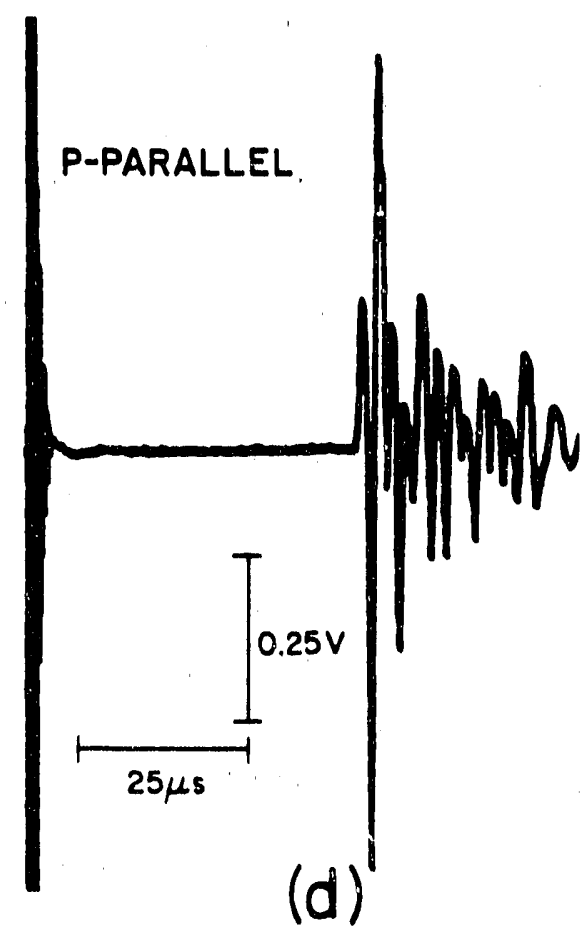

Figure 3-6. Waveforms Obtained During Crack Closure and Healing for Test 5. Initial Waveforms for P-Perpendicular (a) and P-Parallel (b), and Waveforms Obtained After 3 Days at Pressure for P-Perpendicular (c) and P.Parallel (d).

$17 / 18$ 


\subsection{RESULTS}

\subsection{CONSTANT STRAIN-RATE TRIAXIAL LOADING DATA}

\subsubsection{Stress-Strain Data}

Figure 4-1 shows the stress-strain curves obtained during the constant strainrate triaxial loading segment. Through the end of this segment, all specimens were treated identically. A large amount of scatter exists among nominally identical tests. At 0.5 percent axial strain, axial load varies by as much as $3 \mathrm{MPa}$ or 20 percent. The scatter is attributed to specimen-to-specimen variability.

\subsubsection{Amplitude and Velocity Data}

The normalized amplitude changes observed during the constant strain-rate triaxial test segments are shown in Figures 4-2a and 4-2b for compressional waves traveling perpendicular, $P_{\perp}$, and parallel, $P_{\|}$, to the specimen axis, respectivaly. $P_{\perp}$ amplitudes initially increase but then decay significantly within the first 0.2 percent axial strain. $P_{\|}$amplitudes increase substantially and then decay once deformation exceeds 0.1 percent axial strain.

Normalized velocities are given in Figures 4-3a and 4-3b for compressional waves traveling perpendicular and parallel to the direction of maximum compression, respectively. Velocities increase initially only for the $P_{\|}$wave. Velocities then decay for both wave directions as axial strain increases.

The test numbers are given in Figures 4-2 and 4-3 to show that there is no correlation between the results obtained during loading and the order in which tests were performed. A correlation is observed, however, between $P_{\|}$results (Figures 4$2 \mathrm{~b}$ and $4-3 \mathrm{~b}$ ) and specimen identification number. The first four numbers that follow the C1X01 specimen identification designation (Table 3-1) specify the sample block from which the specimen was cored and the last two numbers specify the specimen's location within the sample block. Normalized $P_{\|}$velocities at a given axial strain value (Figure 4-3b) are the lowest for tests 3 and 4 from sample block C1X01-04/12. The next two tests, 1 and 7 , were from sample block C1X01-04/1-4. Test 2 from sample block $\mathrm{C} 1 \mathrm{X01}-03 / 1-4$ is next, and tests 5 and 6 , with the highest normalized velocities, were from sample block $\mathrm{C} 1 \mathrm{X} 01-02 / 1-4 . P_{\perp}$ velocities (Figure 4-3a) show no comparable correlation with specimen identification, although tests 3 and 4 plot close together as do tests 5 and 6 and tests 1 and $7 . P_{\|}$amplitudes also show some correlation with specimen identification (Figure 4-2b). Tests $1,3,4$, and 7 were all from C1X01-04 samples. The first 3 tests show similar results but differ from test 7 . Tests 2, 5, and 6 show similar results and were all performed using non-C1X01-04 specimens. $P_{\perp}$ amplitudes (4-2a) show no comparable correlation with specimen identification. 


\section{STRESS-STRAIN CURVES FOR WIPP SALT}

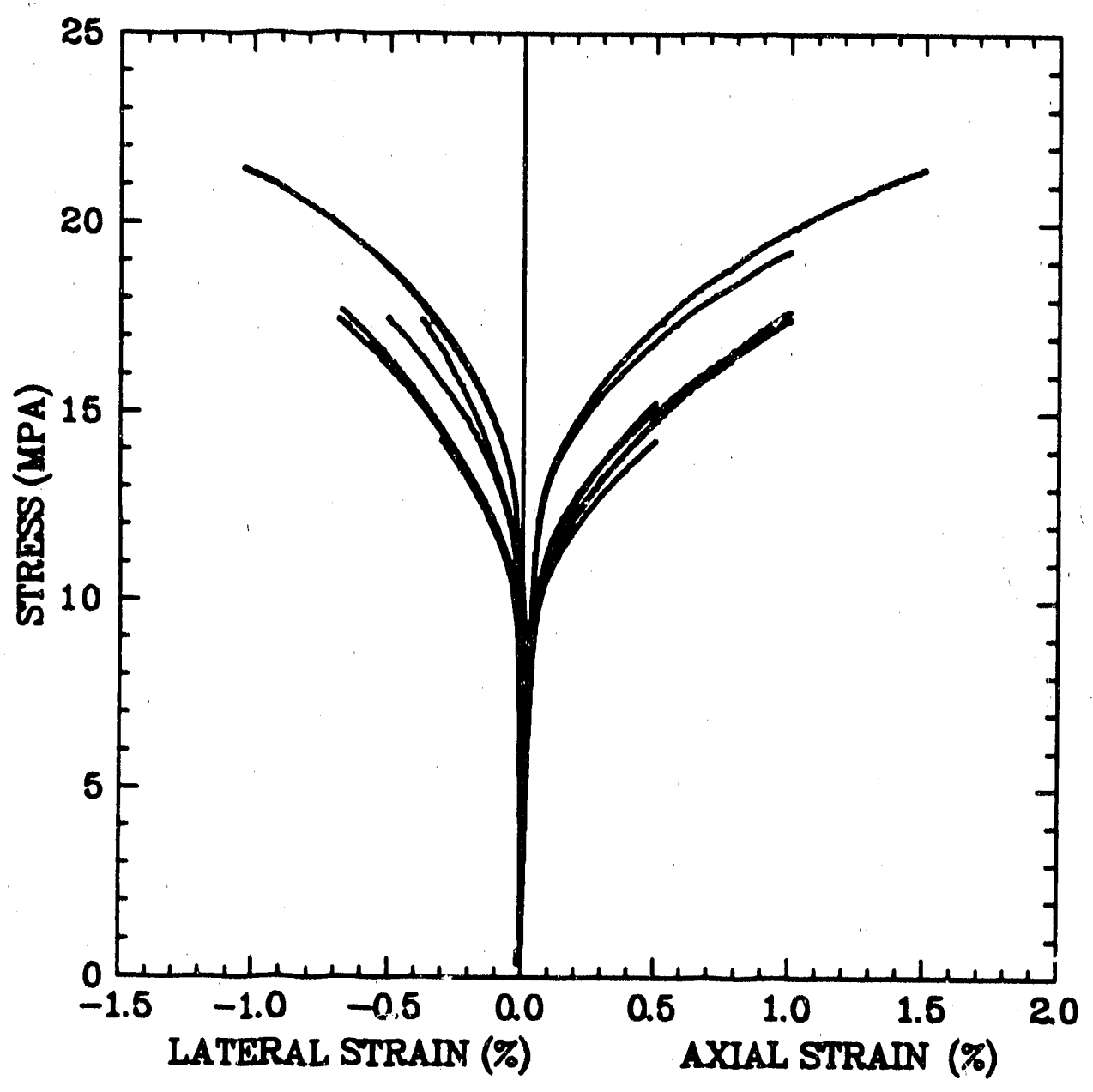

Figure 4-1. Stress-Strain Curves for Constant Strain-Rate Triaxial Compression Test Segments at $0.5 \mathrm{MPa}$ Confining Pressure. Stress is the Axial Stress Minus the Confining Pressure. 


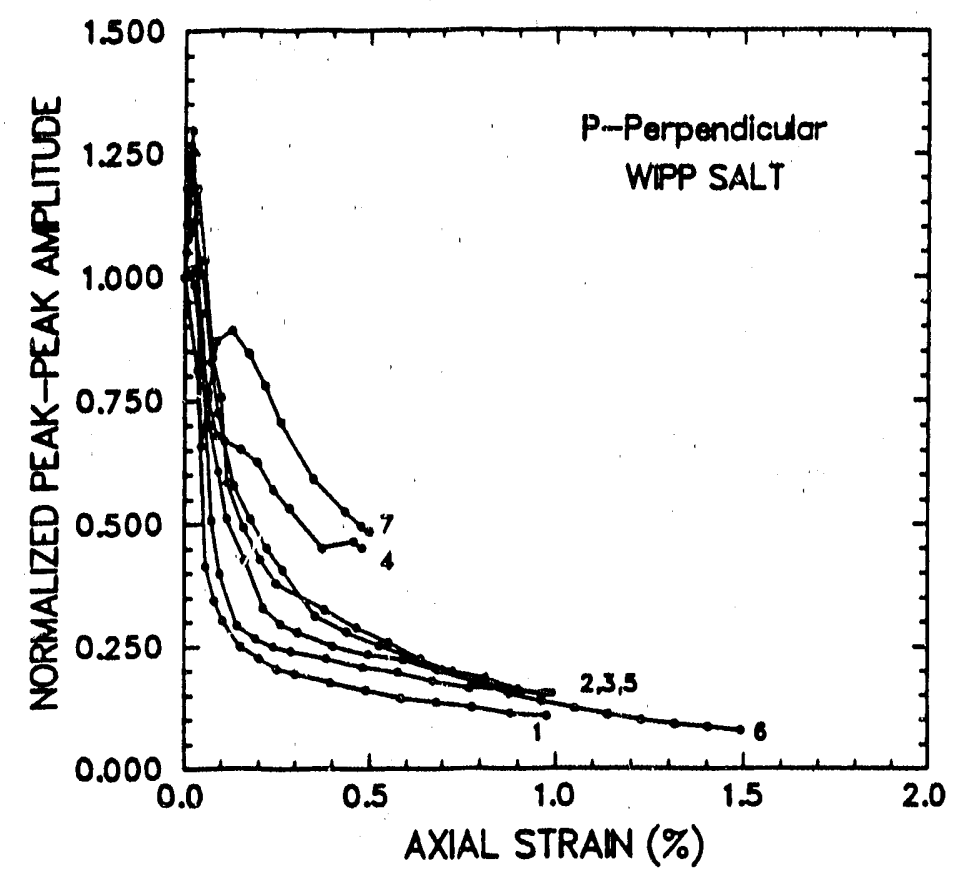

(a)

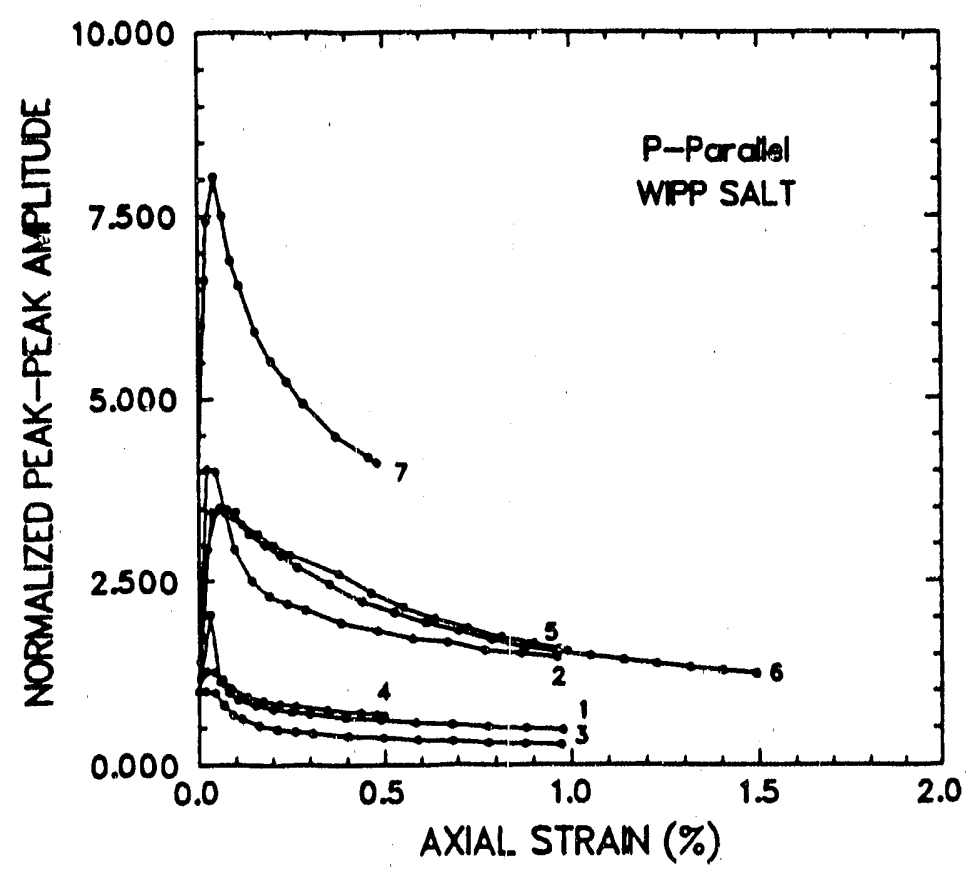

(b)

Figure 4-2. Normalized Peak-to-Peak Amplitudes as a Function of Axial Strain for Constant Strain-Rate Triaxial Compression Test Segments. Test Numbers Co.respond to Table 3-1. 


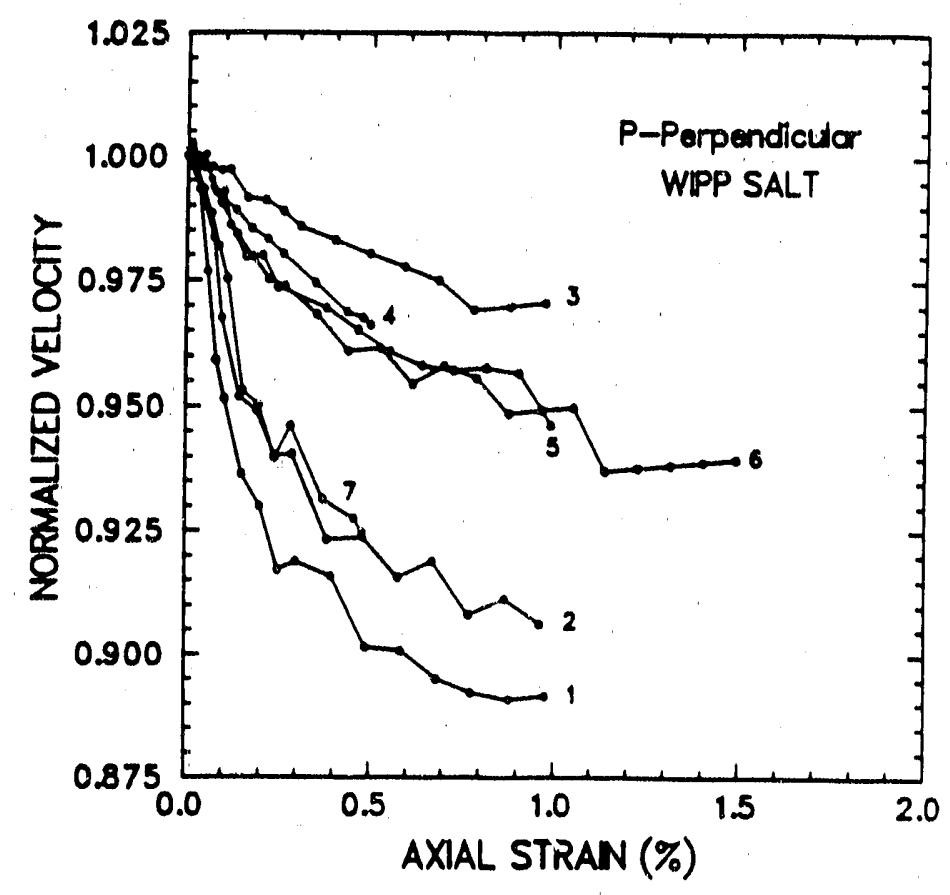

(a)

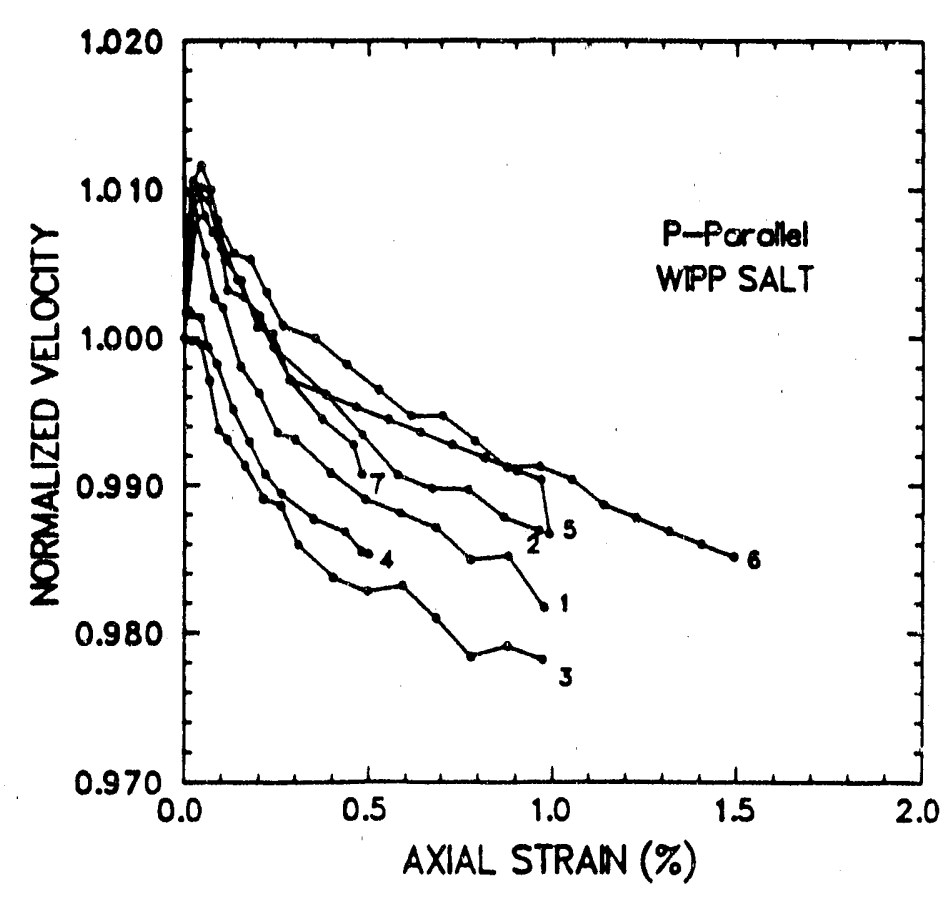

(b)

Figure 4-3. Normalized Velocities as a Function of Axial Strain for Constant Strain-Rate Triaxial Compression Segments. Test Numbers Correspond to Table 3-1. 


\subsection{CRACK CLOSURE AND HEALING PHASE}

\subsubsection{Strain-Time Data}

The axial and lateral strains are given as funciions of time in Figures 4-4 and 4-5, respectively. Plots a through $c$ for each figure show data for different damage levels. Figures 4-4a and 4-5a show data for a damage level of 0.5 percent axial strain, Figures 4-4b and 4-5b show data for a damage level of 1.0 percent, and Figures 4$4 c$ and 4-5c show data for a damage level of 1.5 percent. Figures 4-4b and 4-5b show data for crack closure and healing phase pressures of 5, 10, and $15 \mathrm{MPa}$; the remaining plots show data only for $15 \mathrm{MPa}$. Since compression is positive in sign, a decrease in axial strain implies extension of the specimen parallel to its axis. The data indicate that for the low damage level (Figure 4-4a), the axial strain quickly reaches a stable value. In fact, the axial strain actually goes through a minimum between 0.23 and 2.7 days and then begins to increase. At higher damage levels, axial strains continue to decrease (i.e., the specimen lengthens) for the duration of the test. For the lowest pressure (Figure 4-4b), the axial strain-versus-time curve gocs through a minimum between 1.6 and 2.1 days and then increases. For higher pressures, the axial strains continue to decrease for the duration of the test. The lateral strains (Figure 4-5) show continued compression as a function of time for all pressures and damage levels. The axial strains induced at pressure are much smaller than the lateral strains. Volumetric strains during the crack closure and healing phase therefore show continued compression.

\subsubsection{Amplitude Changes as a Function of Damage Level and Pressure}

Normalized peak-to-peak amplitude data for the crack closure and healing phase of each test are shown in Figures 4-6a through 4-6d. The two upper plots show amplitude changes for tests at different pressures. The lower plots show amplitude changes for tests at different damage levels. The left two plots give $P_{\perp}$ data and the right two show $P_{\|}$data. The recovery of amplitudes shows a clear correlation with damage level for both $P_{\perp}$ and $P_{\|}$(Figures 4-6c and 4-6d). The lower the damage level, the higher the normalized peak-to-peak amplitude at the start of crack closure and healing, the greater the rate of amplitude recovery, and the higher the normalized peak-to-peak amplitude at the end of the closure and healing phase.

There is no clear correlation between amplitude recovery and pressure (Figures 4-6a and 4-6b). It had been anticipated that the higher the pressure, the greater would be the recovery. The $15 \mathrm{MPa}$ tests show the most recovery, as expected. Surprisingly, the $5 \mathrm{MPa}$ test shows more recovery than the $10 \mathrm{MPa}$ test. This apparent diserepancy may be explained by specimen-to-specimen variability in lateral strain. Stress-strain curves for all specimens taken to 1.0 percent axial strain are shown in Figure 4-7. This figure shows that the $5 \mathrm{MPa}$ test specimen underwent much less lateral strain than did the $10 \mathrm{MPa}$ test specimen. Figures $4-6 c$ and 4-6d show that the smaller the induced strain, the greater the amplitude 


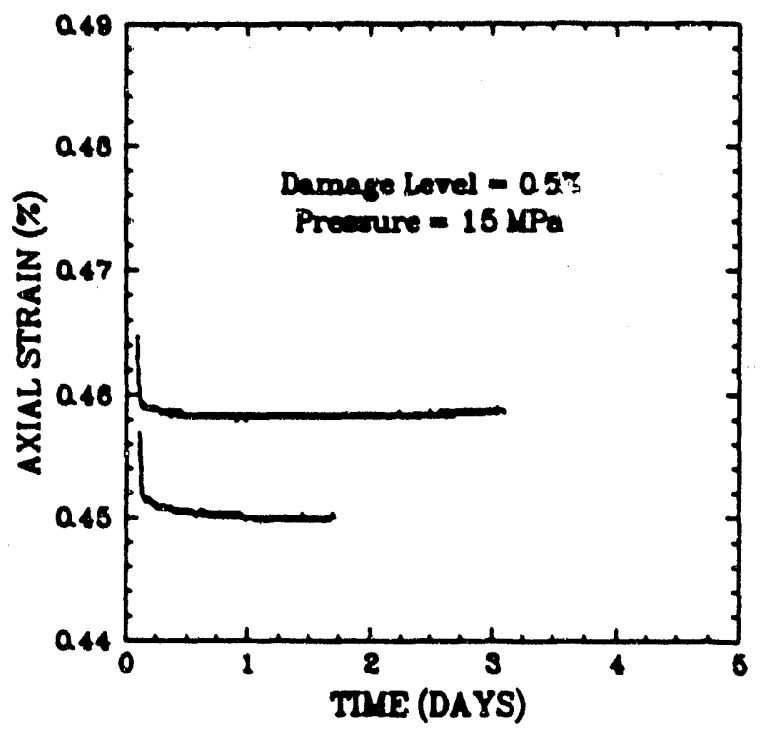

(a)

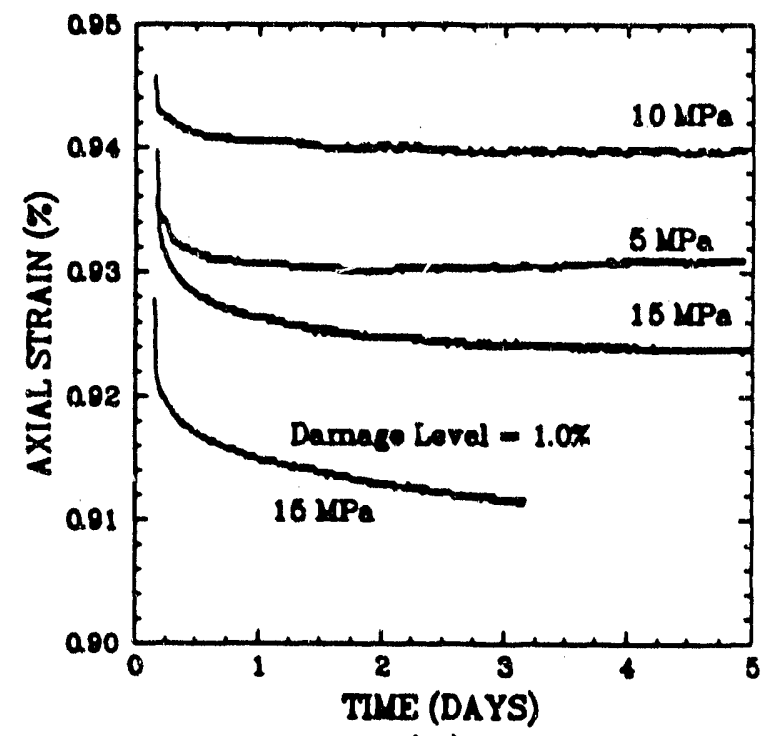

(b)

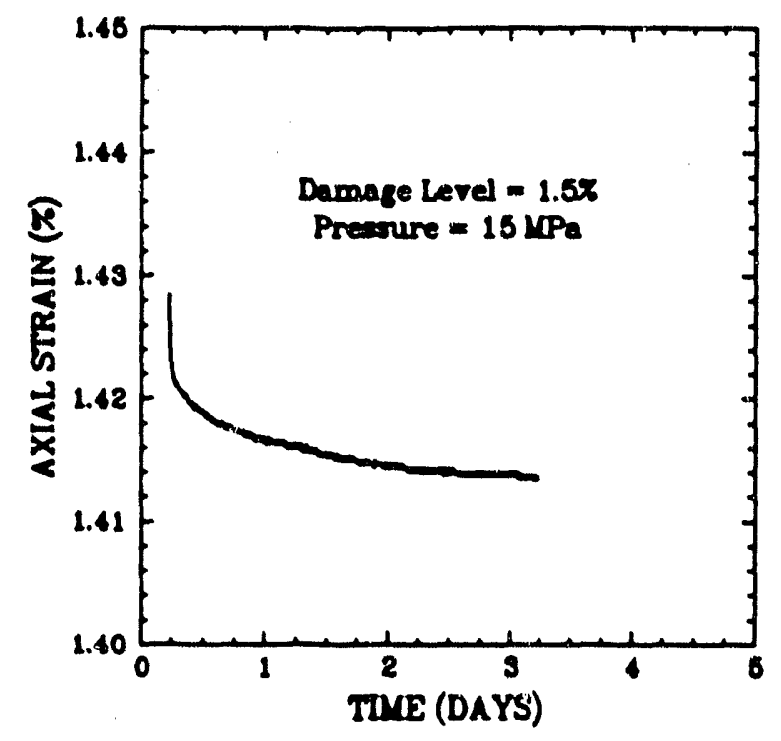

(c)

Figure 4-4. Axial Strains as a Function of Time During the Crack Closure and Healing Segment: (a) Damage Level of 0.5 Percent, (b) Damage Level of 1.0 Percent, and (c) Damage Level of 1.5 Percent. 


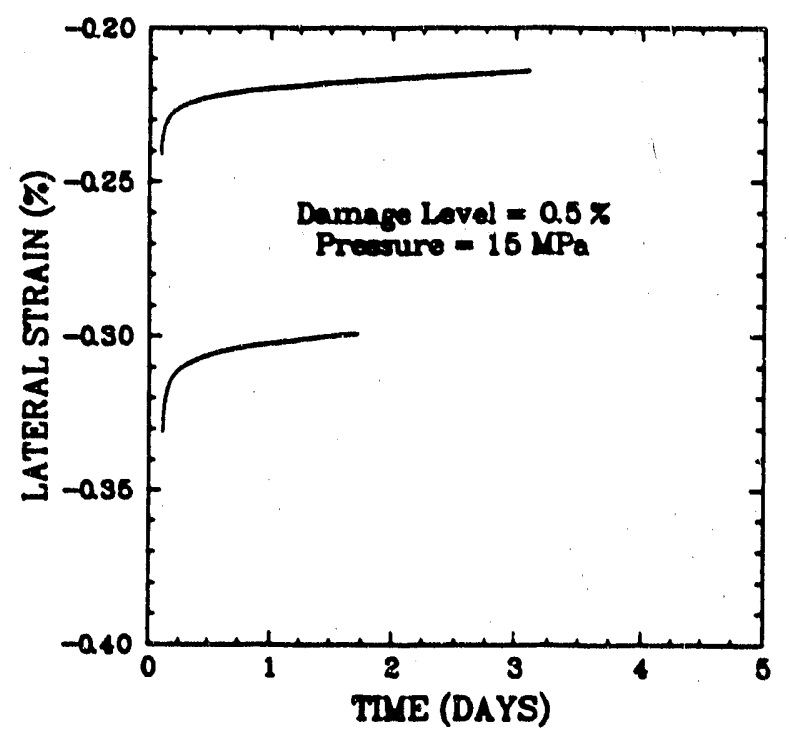

(a)

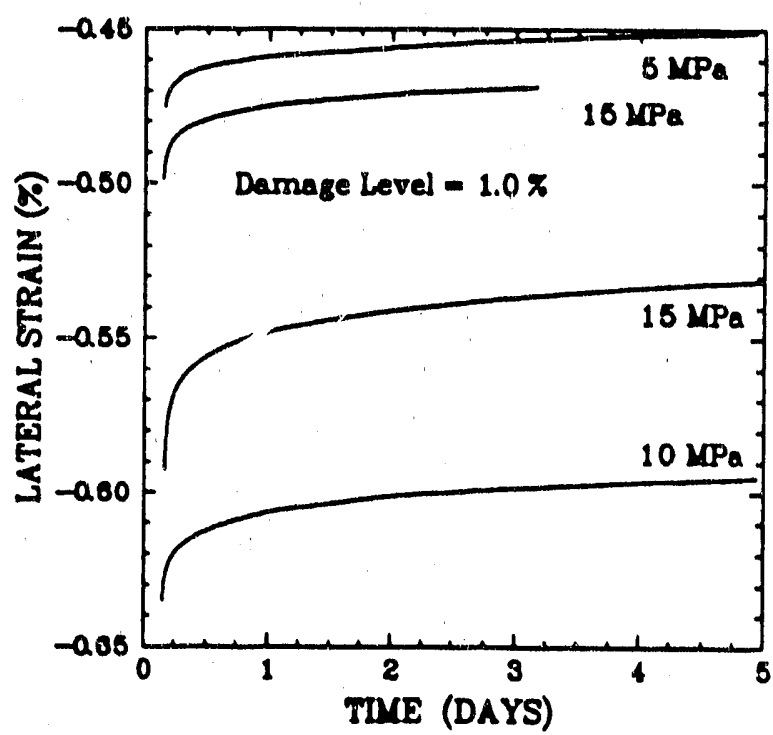

(b)

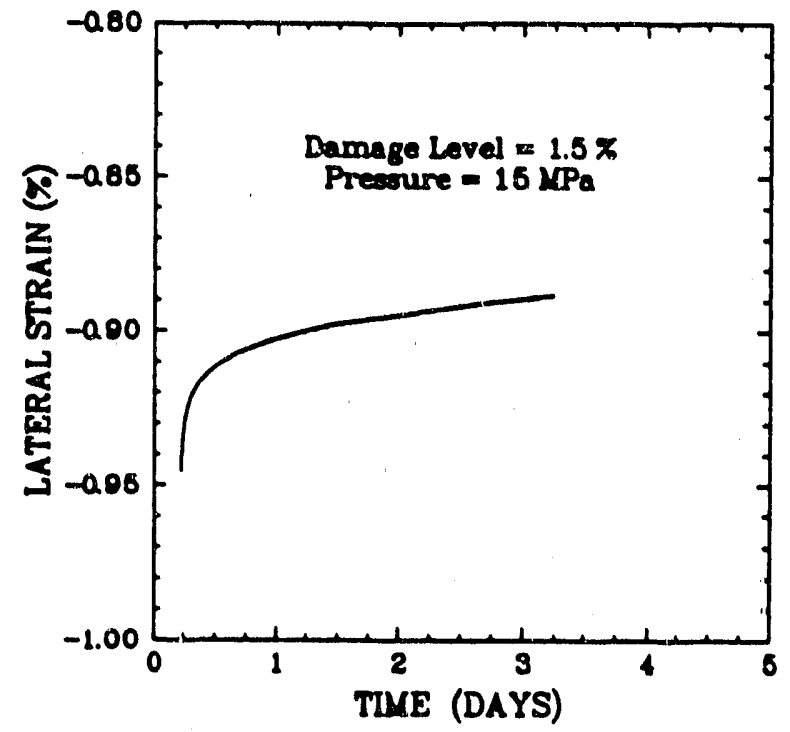

(c)

Figure 4-5. Lateral Strains as a Function of Time During the Crack Closure and I..ealing Segment: (a) Damage Level of 0.5 Percent, (b) Damage Level of 1.0 Percent, and (c) Damage Level of 1.5 Percent. 


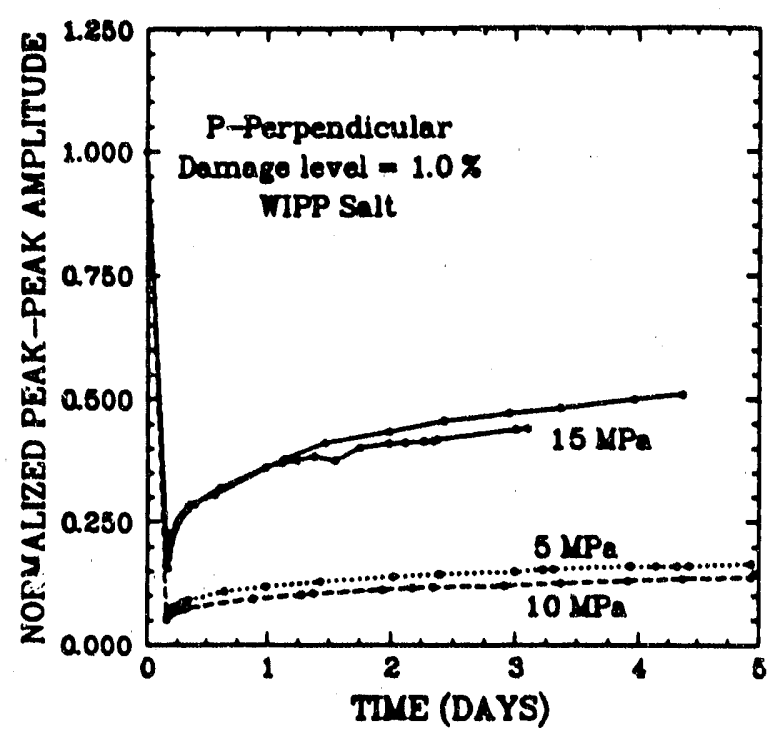

(a)

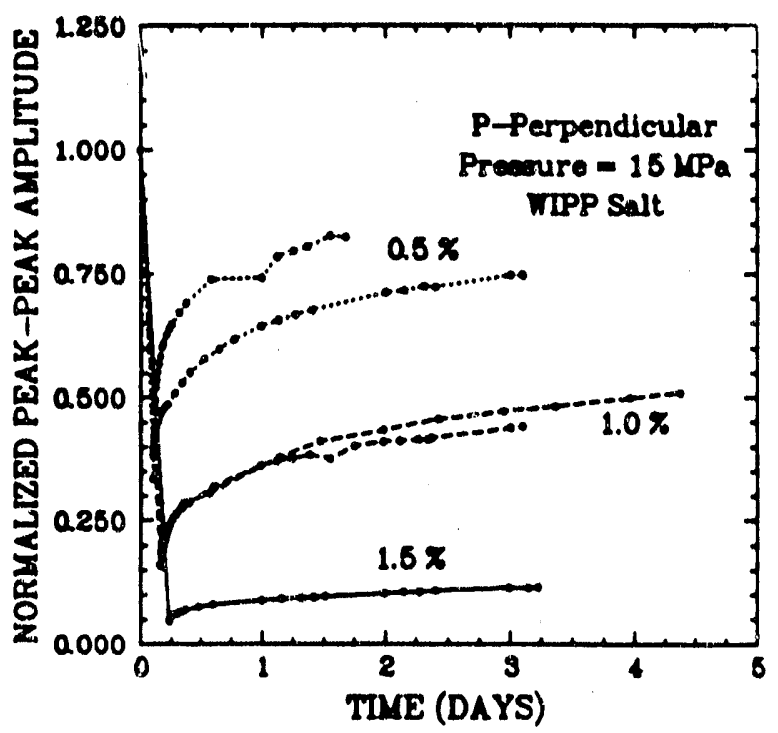

(c)

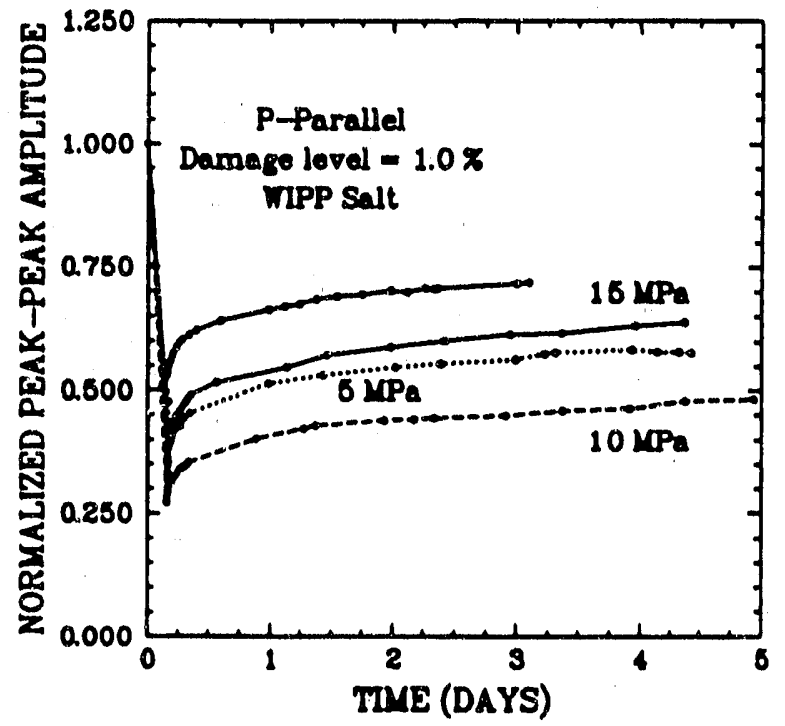

(b)

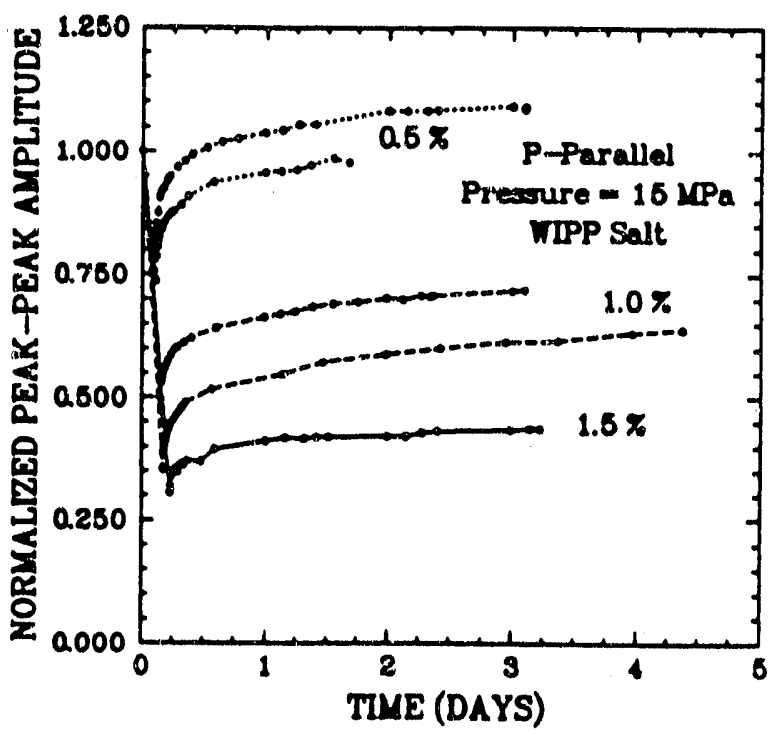

(d)

Figure 4-6. Normalized Peak-to-Peak Amplitudes as Functions of Time During the Crack Closure and Healing Phase. 
STRESS-STRAIN CURVES FOR TESTS TO 1.0 PERCENT AXIAL STRAIN

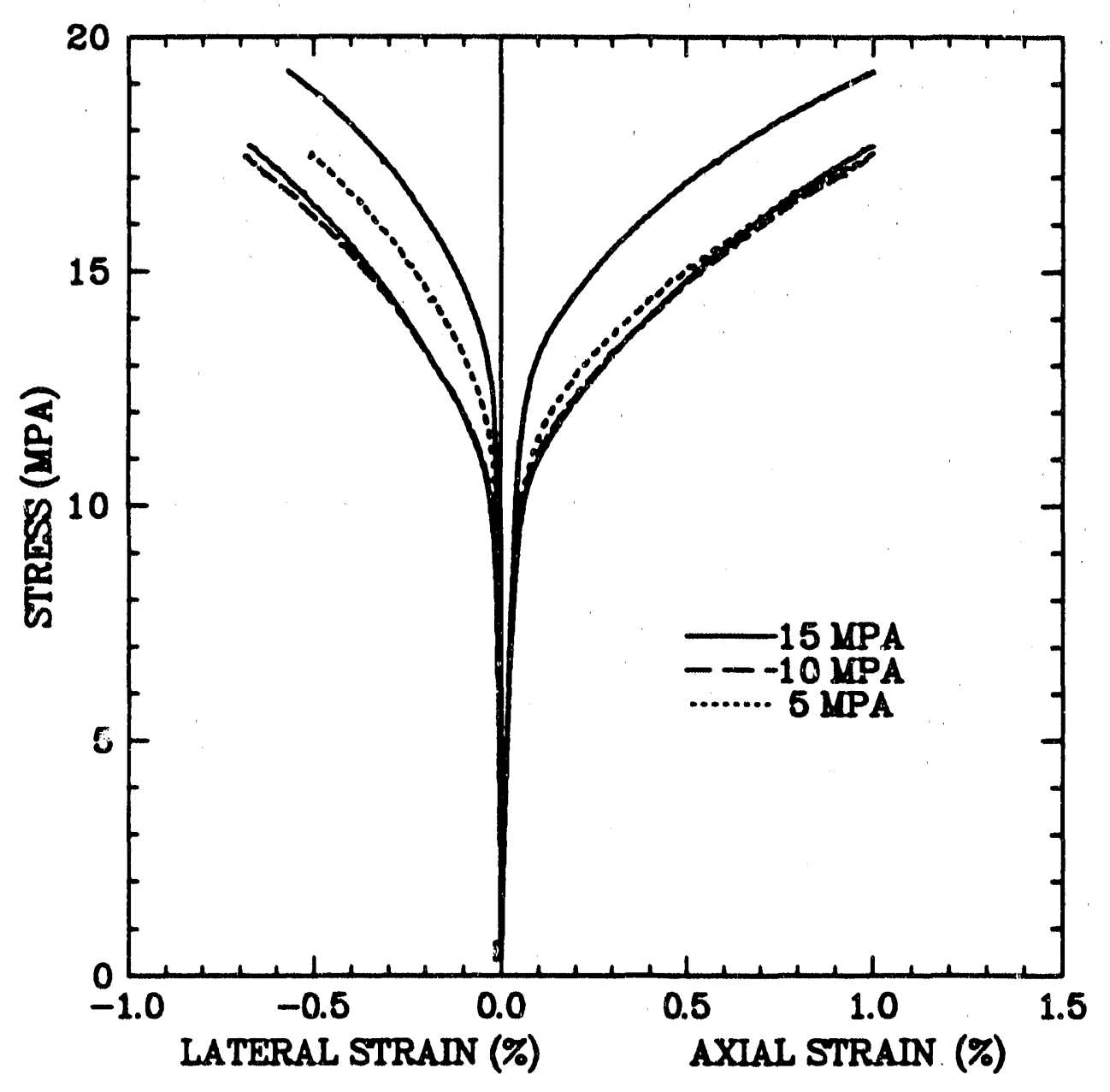

Figure 4-7. Stress-Strain Curves for All Tests Taken to 1.0 Percent Axial Strain. 
recovery. Therefore, the greater recovery of the $5 \mathrm{MPa}$ test specimen relative to the $10 \mathrm{MPa}$ test specimen may be linked to the relatively small lateral strains induced in the $5 \mathrm{MPa}$ test specimen.

\subsubsection{Velocity Changes as a Function of Damage Level and Pressure}

Normalized velocity data for the crack closure and healing phase of each test are shown in Figures 4-8a through 4-8d. The two upper plots show velocity changes for tests at different pressures. The lower plots show velocity changes for tests at different damage levels. The left two plots are $P_{\perp}$ data and the right two include $P_{\|}$data. Although amplitude data did not show a clear correlation with pressure, the recovery of velocities does correlate with pressure (Figures 4-8a and 4-8b). The higher the pressure, the greater the normalized velocity throughout the closure and healing phase. The velocity data also show a correlation with damage level (Figures 4-8c and 4-8d). The smaller the damage level, the higher the normalized velocity during closure and healing. 


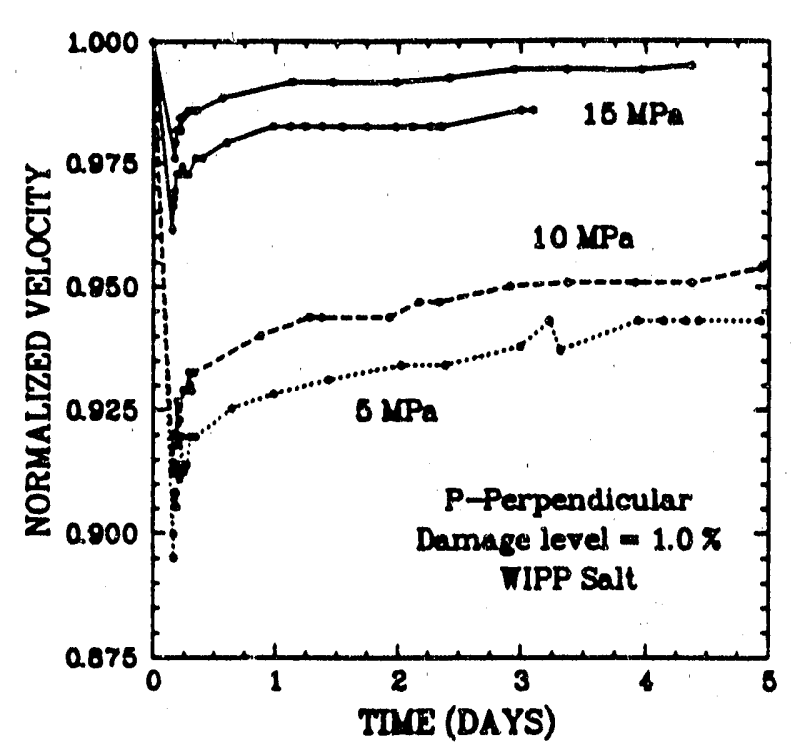

(a)

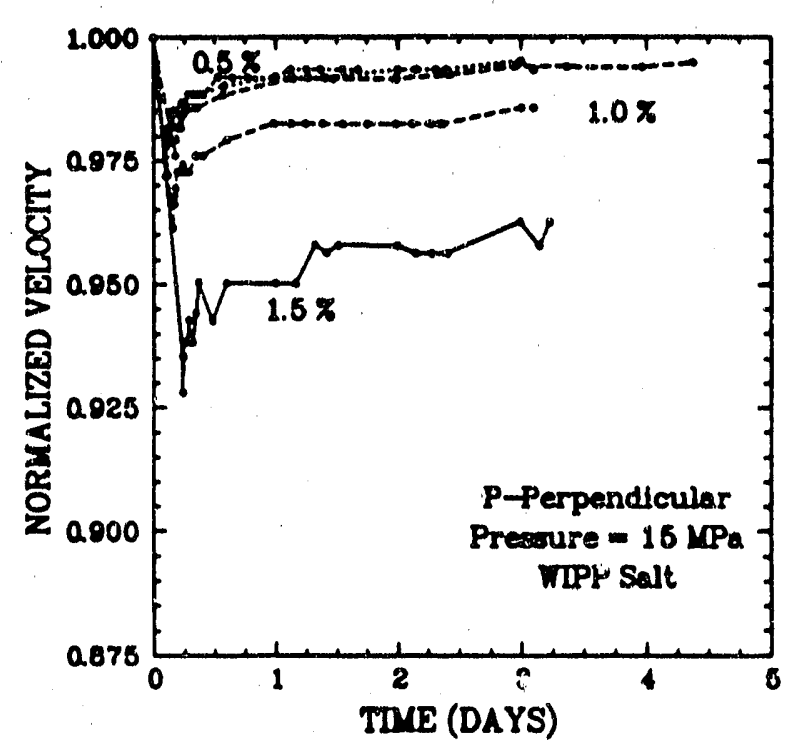

(c)

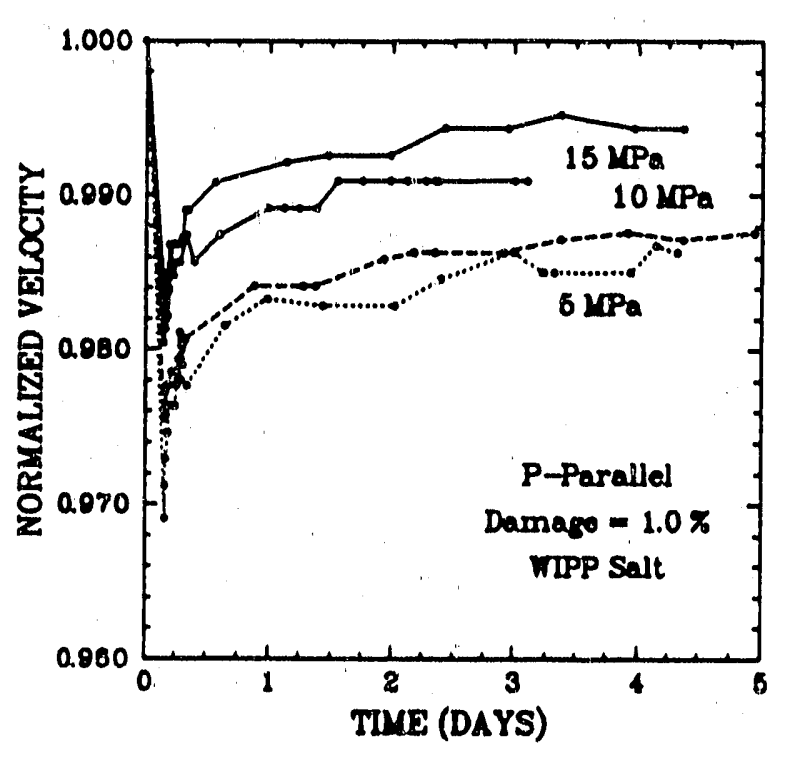

(b)

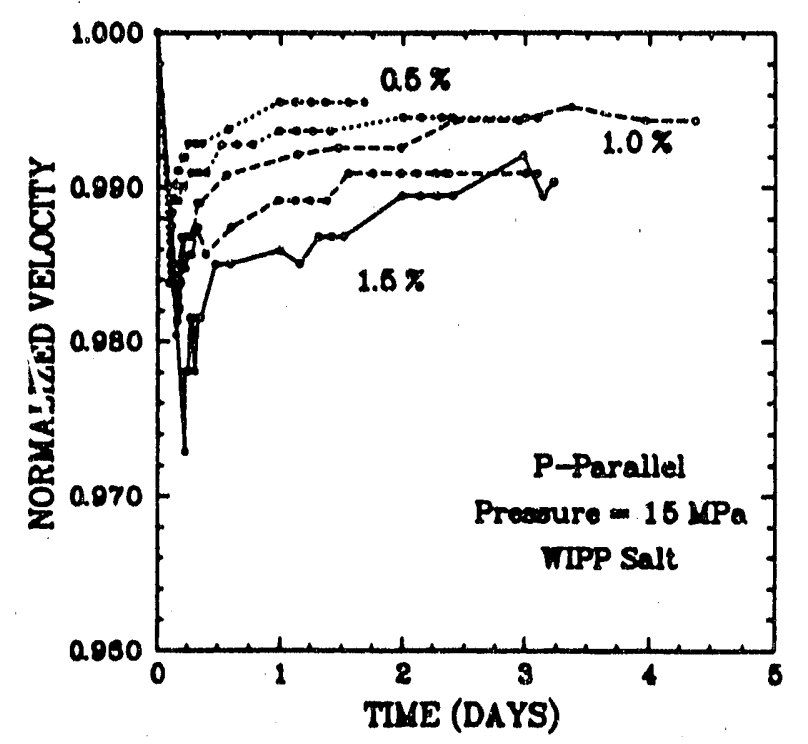

(d)

Figure 4-8. Normalized Velocities as Functions of Time During the Crack Closure and Healing Phase. 


\subsection{DISCUSSION}

\subsection{RELEVANT MECHANISMS FOR WAVE ATTENUATION AND VELOC- ITY CHANGES}

Granryd et al. [1983] and Shea and Hanson [1988] show that whereas both velocity and attenuation are affected by crack development, wave attenuation is the more sensitive indicator. Wave attenuation due to cracks is caused by both scattering of energy at crack surfaces and frictional dissipation. Scattering is the reflection of energy off crack surfaces due to acoustic impedance mismatch. Frictional dissipation occurs when a seismic wave causes sliding' along crack surfaces and grain boundaries. Dissipation affects cracks which are slightly open. If cracks are tightly shut, a seismic wave will not provide enough force to overcome friction and cause slippage. If cracks are wide open, crack walls can vibrate with no losses to friction, and therefore no dissipation.

\subsection{INTERPRETATION OF DATA}

The strain, velocity, and amplitude data are interpreted in terms of changes in the crack population occurring during constant strain-rate triaxial testing and during subsequent crack closure and healing. The crack population may be affected solely by brittle deformation processes, or it may also be influenced by plastic deformation of the specimen microstructure. During the constant strain-rate triaxial test segment (Segment 2 of Figure 3-3), the application of a deviator stress appears to close cracks oriented perpendicular to the direction of maximum compression. This closure, along with better coupling between the specimen and platens, causes the initial increases in the amplitudes and velocities of $P_{\|}$during loading as seen in Figures 4-2b and 4-3b. The extremely large increase in $P_{\|}$amplitudes seen in some tests is attributed to poor initial contact between the specimens and platens, causing very low initial values. This crack closure is also inferred to be responsible for the increase in amplitude of $P_{\perp}$ seen in Figure 4-2a through a decrease in frictional dissipation. The velocity of $P_{\perp}$ does not increase upon loading because velocity is not affected by a change in frictional dissipation. Crack closure during segment 2 implies that the 1-week $20 \mathrm{MPa}$ preconsolidation was not effective in closing all cracks. As the specimen continues to deform, cracks open primarily parallel to the specimen axis causing the amplitudes and velocities of both $P_{\|}$and $P_{\perp}$ to decrease. These cracks should principally affect $P_{\perp}$, and so the large decreases in $P_{\|}$velocity and amplitude were unexpected. Since wave attenuation is more affected by crack development than are velocities, the amplitudes drop more quickly than the velocities for both wave directions. Amplitude changes become essentially independent of deformation at higher deformation levels. 
As the specimen is taken up to pressure (Segment 3 in Figure 3-3), cracks begin to close and perhaps to heal. Both processes (closure and healing) continue over time at pressure. The recovery of amplitudes depends very little on pressure but appears to be a sensitive function of damage level (Figure 4-6). Specimens with low damage levels recover quickly and substantially, whereas the specimen with a high damage level shows very little amplitude recovery. This is consistent with the amplitude changes observed during loading (Figure 4-2). As damage is induced (cracks propagate), crack walls separate, causing large changes in wave attenuation. Once crack walls are separated, further widening of the crack has little effect on signal attenuation. During crack closure and healing, the process reverses. For specimens with high damage levels, cracks are wide open and a small amount of closure does not affect ultrasonic properties. Once crack walls are close to contacting, a small amount of closure will cause a large change in attenuation.

Wave velocities over time at pressure appear to be both pressure dependent and damage-level dependent (Figure 4-8). The dependence of velocity on damage level is less pronounced than was the dependence of amplitude on damage level. This again follows from the data recorded during loading. Examination of the data shown in Figures 4-2 and 4-3 shows that the change in velocity per unit increase in axial strain is more constant with increasing axial strain (or damage level) than is the change in amplitude per unit increase in axial strain. When the process of crack development reverses during healing, the change in velocity with decreasing damage level should not be substantially different for specimens of high and low damage levels.

Two possible explanations are offered for the inverse correlation between the recovery of ultrasonic properties and damage level during crack closure and healing. The first interpretation relies solely on brittle deformation processes. For cracks to close and heal quickly, crack walls must remain near to their original geometries so that they can touch and fuse. For higher levels of damage, crack surfaces may become offset and may not remate immediately upon pressurization. Debris can fall into a crack and keep it open. Specimens taken to low damage levels have cracks that are not as fully developed as those in specimens taken to high damage levels. These cracks are more likely to retain their original configurations and remain free of debris. They are therefore more likely to close and heal relatively quickly and undergo larger recoveries in wave attenuation when subjected to confining pressure. Complete recovery of ultrasonic characteristics is expe 'ted in all specimens for all damage levels provided the hydrostatic stress is maintained for a sufficient period of time.

The second possible explanation involves plastic deformation mechanisms. As specimens are taken to higher levels of strain, the microstructure develops. At strain levels of less than 1.0 percent, the dislocation density begins to increase; at slightly higher strain levels, the dislocations begin to cluster along crystallographic planes. These processes harden the microstructure through dislocation tangles that provide obstacles to further dislocation movement and through dislocation pileups at grain boundaries and crack surfaces that inhibit further deformation. Specimens 
that are taken to low damage levels experience primarily dislocation multiplication. When differential stress is released and pressure is applied to induce crack closure and healing, the dislocations are relatively mobile and can move to accommodate the new stress field. For specimens taken to higher damage levels, the hardened and tangled microstructure around the crack tips inhibits dislocation mobility and slows creep closure of cracks. Full recovery of ultrasonic characteristics is expected if the healing pressure is applied for a longer period of time.

These two possible explanations for the relationship between damage and recovery of ultrasonic amplitudes are not mutually exclusive. It is most likely that the damage and healing processes involve both brittle and plastic deformation mechanisms. Regardless of the mechanism, the relation between the recovery of ultrasonic properties and damage level implies that specimen preconsolidation at $20 \mathrm{MPa}$ for 1 week (see Section 3.2.3) is effective only for low damage levels.

The extent of crack healing should be apparent from a comparison of the state of the material before and after the crack closure and healing phase pressurization. When the specimen is depressurized (Segment 5 in Figure 3-3), some of the closed cracks reopen. Those that remain closed will be defined as healed. Data obtained at Points $B$ and $E$ should differ because some cracks healed at pressure. A comparison of the material at Points $B$ and $E$ should therefore indicate the extent of crack healing. The ratio of amplitudes obtained at Point $E$ divided by the amplitudes recorded at Point $B$ are plotted in Figures 5-1a and 5-1c as a function of pressure and damage level, respectively. Figures $5-1 \mathrm{~b}$ and $5-1 \mathrm{~d}$ show the ratio of velocities obtained at Points $\mathrm{E}$ and $\mathrm{B}$ as a function of pressure and damage, respectively. It was expected that the ratios would always be greater than or equal to one. The higher the ratio, the greater the extent of healing during the closure and healing phase. Most ratios are greater than one, but surprisingly, many are less than one. This is attributed to experimental uncertainty, although the uncertainty is much larger than expected based on pressure cycling of aluminum (Figures 3-5a and 3$5 \mathrm{~b})$. The uncertainty in $P_{\perp}$ is attributed in part to changes in acoustic coupling between the specimen and transducers during depressurization. Transducer coupling is sensitive to deformations of crystals underneath the transducer face, and so it is affected by crystal to crystal variations in strain during depressurization.

Owing to the experimental uncertainty associated with these data, no firm conclusions can be drawn about the proportion of closed cracks that also healed. It is observed that the healing index, E/B, shows some pressure dependence (Figures 5-1a and 5-1b). The higher the pressure, the greater the ratio for both $P_{\perp}$ and $P_{\|}$. Observed changes in E/B as a function of damage level are less consistent (Figures 5-1c and 5-1d). The amplitude ratio for $\mathrm{E} / \mathrm{B}$ decreases with increasing damage level for $P_{\|}$but increases with increasing damage level for $P_{\perp}$ (Figure 5-1c). The velocity ratio shows the opposite trend (Figure 5-1d). The velocity ratio for E/B increases with increasing damage level for $P_{\|}$and decreases with increasing damage level for $P_{\perp}$. 


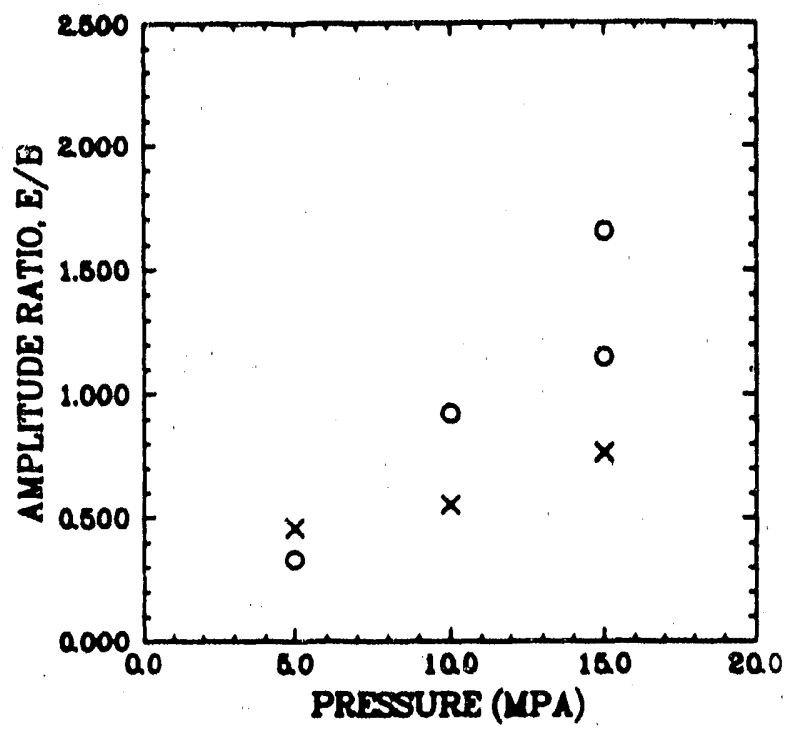

(a)

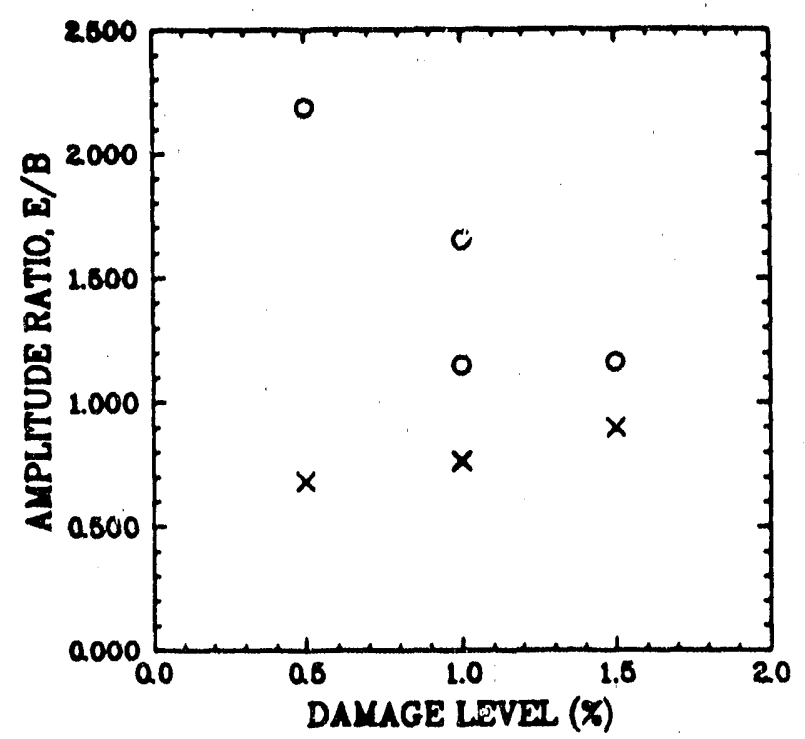

(c)

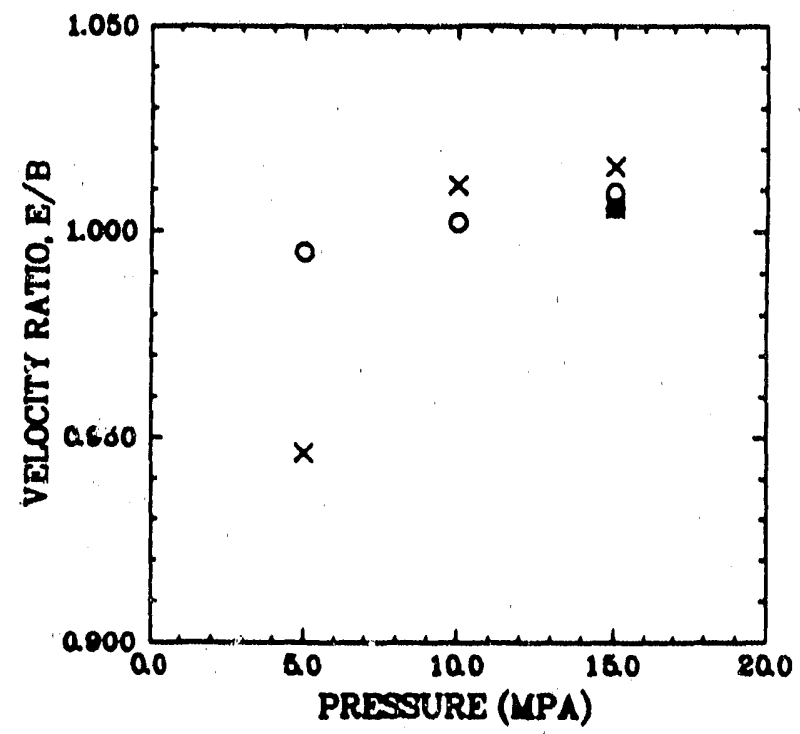

(b)

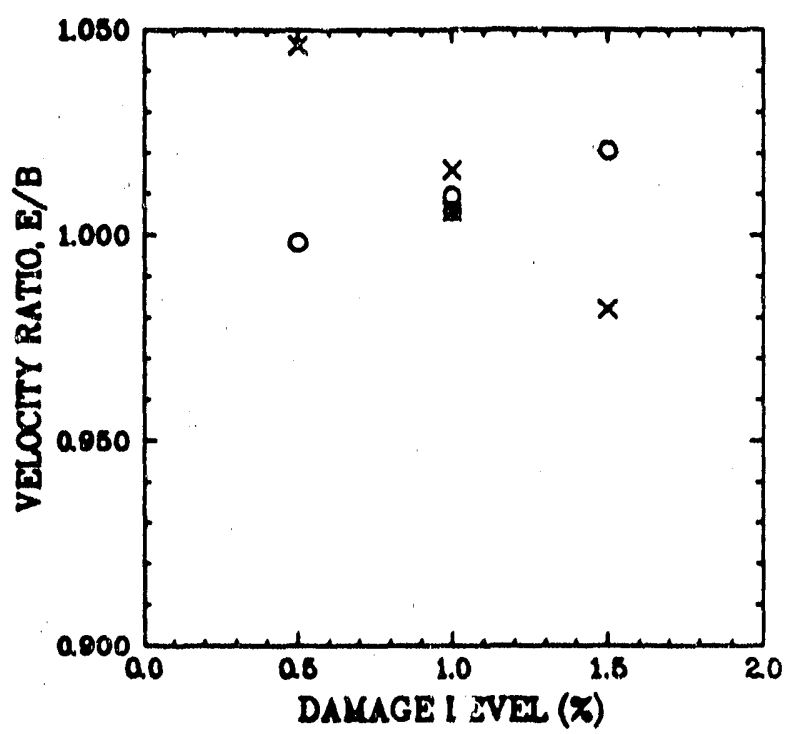

(d)

Figure 5-1. Ratio of Amplitudes at Points $E$ and $B$, and Ratio of Velocities at Points $\mathrm{E}$ and $\mathrm{B}$ as a Function of Pressure and Damage Level. $P_{\perp}: \mathrm{X}_{i}$ $P_{\|}:$O. 


\subsection{SUMMARY AND CONCLUSIONS}

Two experiments were performed to examine crack closure and healing as a function of time at different pressures and for different damage levels. Cracks were introduced into specimens of WIPP salt during constant strain-rate triaxial testing at low confining pressure. Three levels of maximum axial strain were used, corresponding to the three damage levels. The cracks were closed and perhaps partially healed by subjecting the specimens to hydrostatic stress. For one of the damage levels, three values of hydrostatic stress were used. Crack closure and healing were monitored using ultrasonic compressional wave velocity and amplitude attentuation measurements. During crack closure and healing, velocities and amplitudes would partially recover, approaching the values they had in the undamaged state. Tests were performed in a computer-controlled, servohydraulic test system. A load path test control program was used to apply the load path and acquire stress and strain data.

Results showed that the recovery of ultrasonic velocities depended on pressure. As would be expected, the higher the pressure, the greater the velocity recovery during crack closure and healing. Surprisingly, amplitude recovery showed no clear correlation with pressure. This was attributed to specimen to specimen variations. Amplitude recovery depended strongly on damage level. While all tests for which pressure dependence is discussed were taken to the same level of axial strain, different levels of lateral strain were induced in each test.

Both ultrasonic velocity and amplitude attenuation recoveries depended upon damage level. For lioth velocities and amplitudes, recoveries were greatest in the specimens taken to the lowest damage levels. These resuits can be explained in either of two ways: using a model that requires only brittle deformation, or using a model that also includes plastic deformation mechanisms. According to the first model, as damage is introduced, cracks open, causing wave amplitudes to drop substantially. Further widening of the cracks causes relatively small changes in aruplitude. For specimens subjected to higher damage levels, the geometry of the crack walls has more opportunity to change during deformation. Also the higher the damage level, the more likely it is for debris from the crack walls to fall into the crack. Both of these processes, changing crack geometry and the filling of cracks with debris, would cause cracks associated with higher deformation levels to remain open under hydrostatic stress and be less likely to close and heal quickly.

The second interpretation involves increased microstructural hardness for specimens taken to high damage levels. As damage level increases, dislocation tangles and pileups at grain boundaries and crack surfaces inhibit further deformation. When the differential stress is released and pressure is applied, the increased microstructural hardness inhibits creep closure of cracks.

Both data interpretations predict that complete closure and healing of cracks will occur if the pressures are maintained for longer periods of time. 


\subsection{REFERENCES}

Birch, F., 1960. "The Velocity of Compressional Waves in Rocks to 10 kilobars, Part 1," Journal of Geophysical Research, Vol. 65, pp. 1083-1102.

Birch, F., 1961. "The Velocity of Compressional Waves in Rocks to 10 kilobars, Part 2," Journal of Geophysical Research, Vol. 66, pp. 2199-2224.

Costin, L. S., and W. R. Wawersik, 1980. Crack Healing of Fractures in Rock Salt, SAND80-0392, Sandia National Laboratories, Albuquerque, NM.

Granryd, L., I. C. Getting, and H. Spetzler, 1983. "Path Dependence of Acoustic Velocity and Attenuation in Experimentally Deformed Westerly Granite," Geophysical Research Letters, Vol. 10, pp. 71-74.

Gupta, I. N., 1973. "Seismic Velocities in Rock Subjected to Axial Loading Up to Shear Fracture," Journal of Geophysical Research, Vol. 78, pp. 6936-6942.

Hadley, K., 1975. "Azimuthal Variation of Dilatancy," Journal of Geophysical Research, Vol. 80, pp. 4845-4850.

Holcomb, D., 1988. "Cross Hole Measurements of Velocity and Attenuation to Detect a Disturbed Zone in Salt at the Waste Isolation Pilot Plant: Key Questions in Rock Mechanics," Proceedings, 209th U.S. Symposium on Rock Mechanics, University of Minnesota, Minneapolis, MN, Cundall et al. (eds.), A. A. Balkema, Rotterdam, pp. 633-640.

Senseny, P. E., 1987. "Deformation Measurements in Rock Mechanics Using Direct-Contact Extensometers," Proceedings, th Annual Hostile Environments and High Temperature Measurements Conference, Society for Experimental Mechanics, Windsor Locks, CT, March, pp. 94-99.

Shea, V. R., and D. R. Hanson, 1988. "Elastic Wave Velocity and Attenuation as Used to Define Phases of Loading and Failure in Coal," International Journal of Rock Mechanics and Mining Sciences and Geoscience Abstracts, Vol. 25, No. 6, pp. 431-437.

Simmons; G., 1964. "Velocity of Shear Waves in Rocks to 10 kilobars, ${ }^{n}$ Journal of Geophysical Research, Vol. 69, pp. 1123-1130. 
Sobolev, G., H. Spetzler, and B. Salov, 1978. "Precursors to Failure in Rocks While Undergoing Anelastic Deformations," Journal of Geophysical Research, Vol. 83, pp. 1775-1784.

Soga, N., H. Mizutani, H. Spetzler, and R. J. Martin III, 1978. "The Effect of Dilatancy on Velocity Anisotropy in Westerly Granite," Journal of Geophysical Research, Vol. 83, pp. 4451-4458.

Spetzler, H. A., G. A. Sobolev, C. H. Sondergeld, B. G. Salov, I. C. Getting, and A. Koltsov, 1981. "Surface Deformation, Crack Formation and Acoustic Velocity Changes in Pyrophyllite Under Polyaxial Loading," Journal of Geophysical Research, Vol. 10, pp. 1070-1080. 

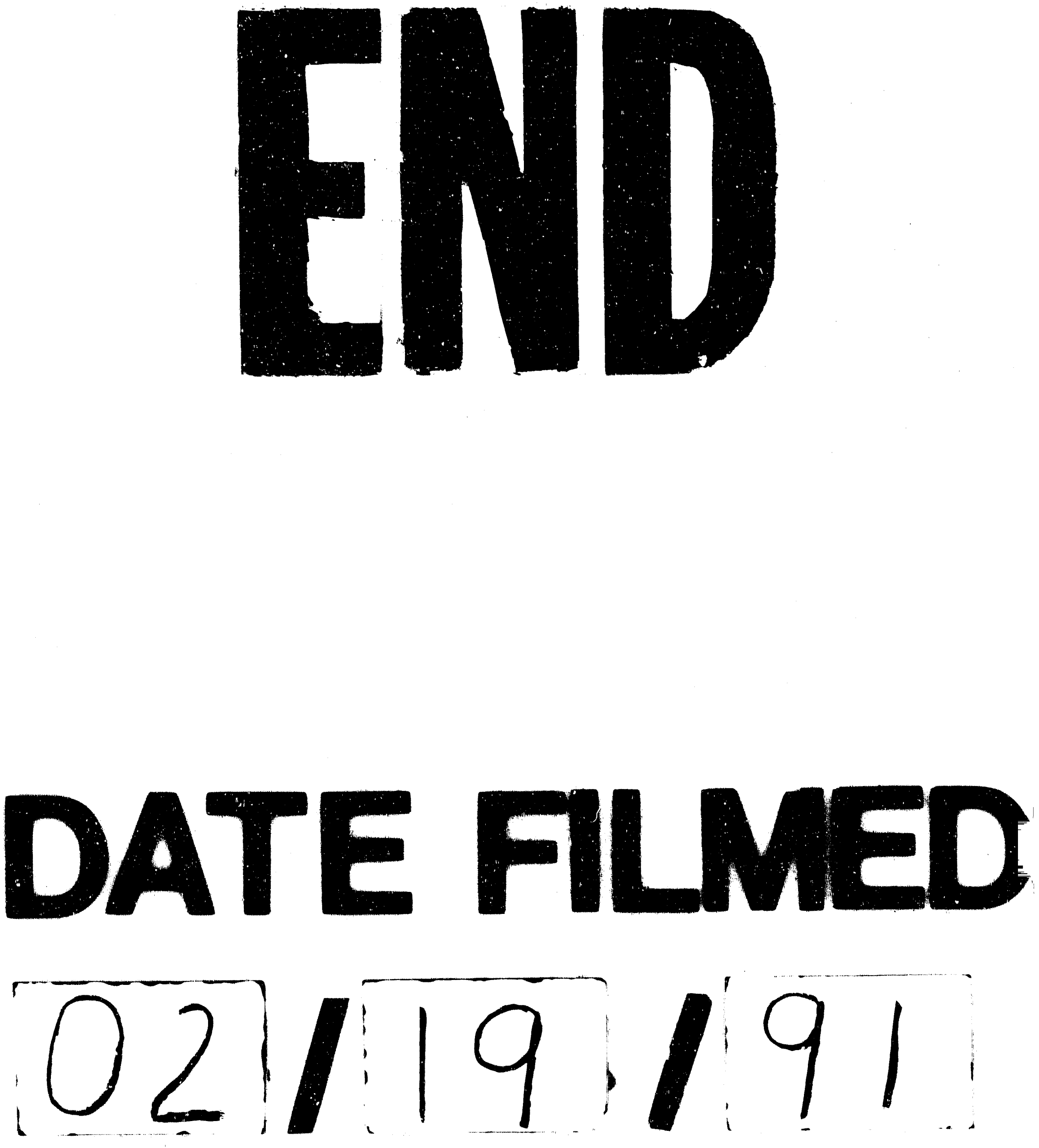
